\title{
THE DEGREE TO WHICH ISLAMIC EDUCATION FIRST TEACHERS EXERCISE THEIR SUPERVISORY: SCHOOL PRINCIPALS AND SUBJECT TEACHERS' PERSPECTIVES
}

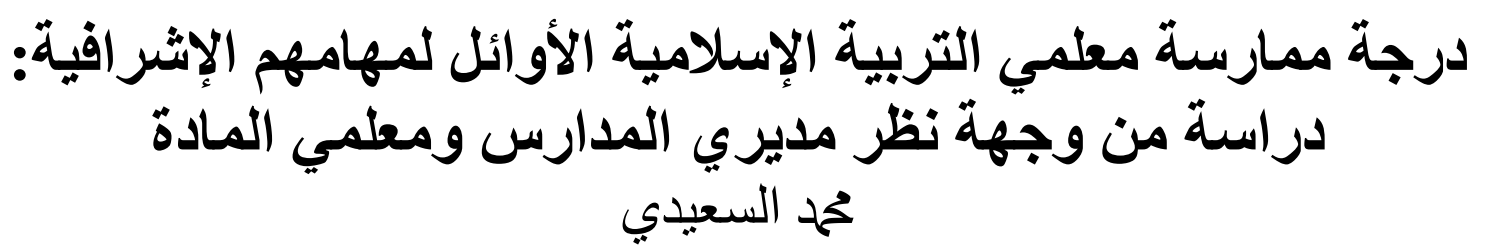

\section{Mohammed Salim Rashid Al-Saeedi}

Ph.D. Candidate at the Faculty of Education, International Islamic University Malaysia (IIUM), msaeedi@su.edu.om

\begin{abstract}
This quantitative study discussed the supervisory practices practiced by the first teachers of Islamic education from the viewpoint of school principals and subject teachers. The problem was represented by the results of many educational studies, to the presence of obstacles in the first teacher preparation program, and to the lack of familiarity of the first teachers in the areas of supervisory practices for the first teacher and his tasks, and that they had not received training on them before, in addition to the best researcher in the educational field as an educational supervisor for the subject of education Islamic, and his participation in the evaluation committees of the first teachers in the Al Batinah North region. Therefore, the study aimed to diagnose the degree of the practice of the first Islamic education teachers in their supervisory tasks from the viewpoint of school principals and subject teachers. The sample of the study consisted of (80) principals, and (170) teachers of Islamic education. The researcher prepared a questionnaire consisting of (54) tasks, which included (6) fields, namely: the field of planning, curricula and teaching methods, educational evaluation, field follow-up, training, human relations and the local community. The most prominent results of the study were: The exercise of supervisory tasks in the field of human relations and the local community was very large, while the degree of the exercise of supervisory tasks in the five supervisory areas came largely.
\end{abstract}

Keywords: supervisory practices, senior teachers, Islamic education

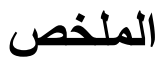

ناقشت هذه الدر اسة الكمية الممارسات الإشر افية التي يمارسها معلمو التربية الإسلامية الأوائل من

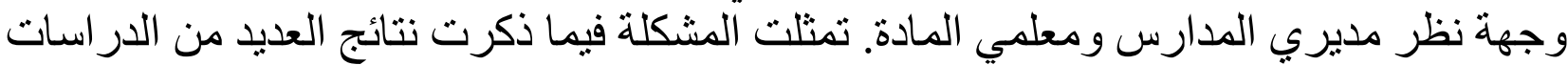
التربوية، إلى وجود معوقات في برنامج إعداد المعلم الأول، و إلى عدم إلمام المعلمين الأوائل

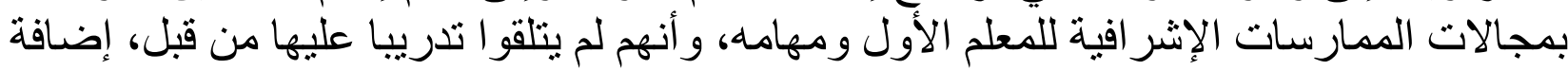
إلى خيرة الباحث في الميدان التربوي كمشرف تربوي لمادة التربية الإسلامية، ومشاركاته في 


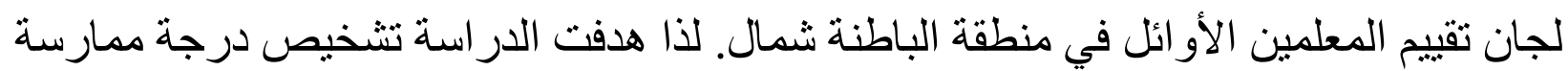

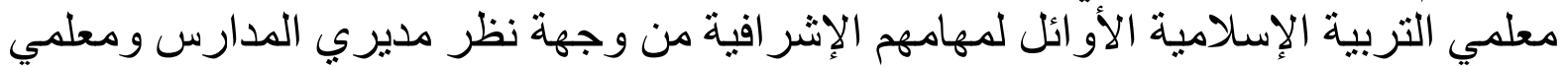

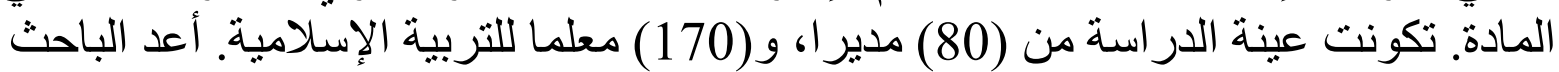

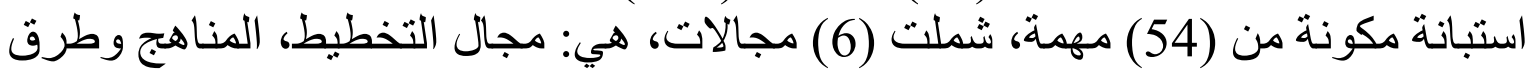

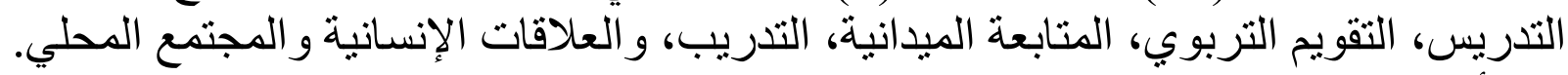

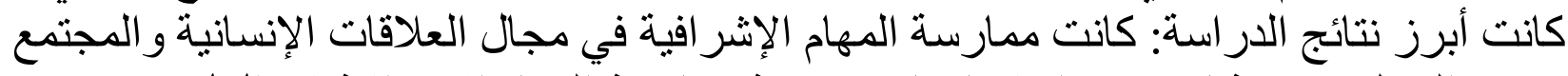

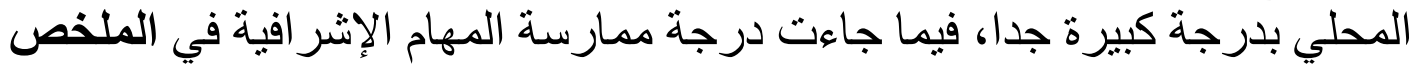

ناقتت هذه الدر اسة الكمية الممارسات الإشر افية التي يمارسها معلمو التربية الإسلامية الأوائل من

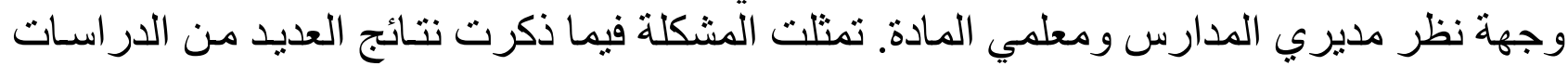

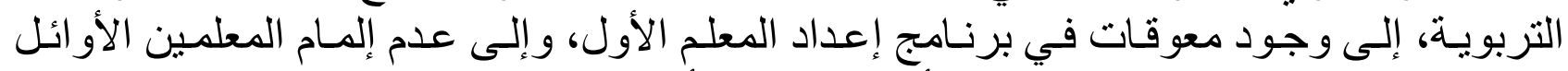

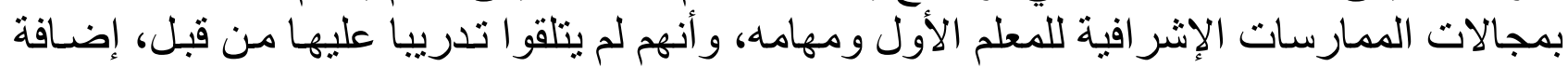

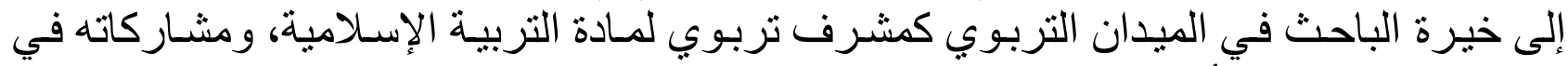

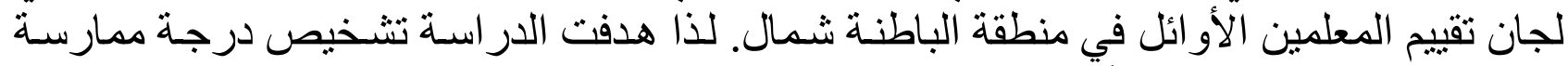

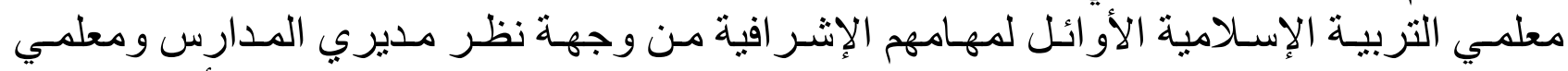

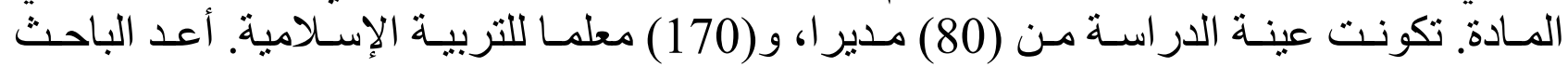

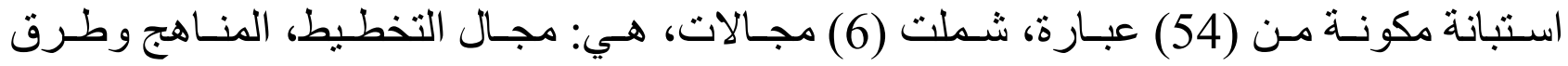

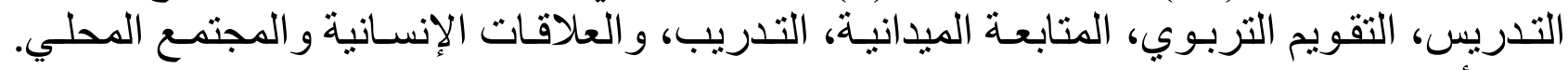

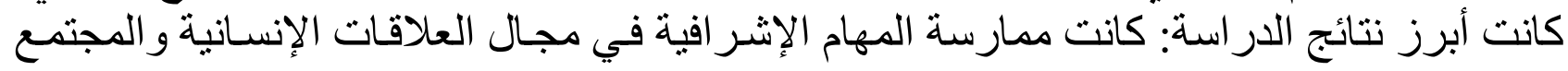

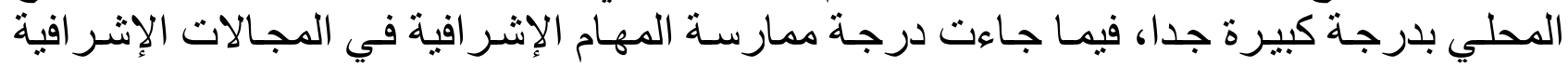
الخمسة بدرجة كبيرة.

كلمات مفتاحية: الممارسات الإشر افية، المعلمون الأوائل، التربية الإسلامية.

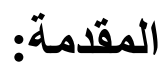

تدعو الاتجاهات التربوية الحديثة إلى جعل الإشراف التربوي عملية مستمرة متكاملة، بحيث يقوم المشرف التربوي بالمتابعة الميدانية لسير العملية التعليمية التعلمية، و العمل على الإنى استثمار الأفكار

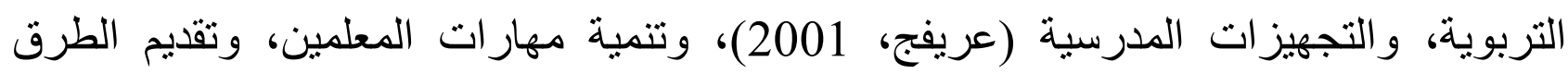

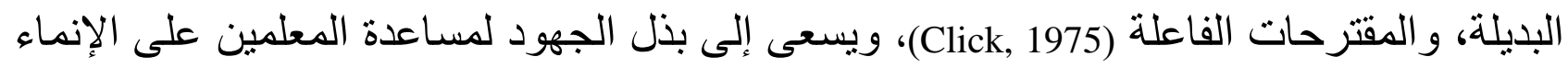

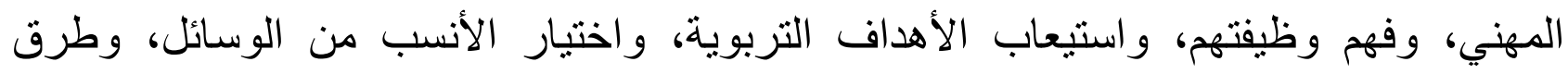

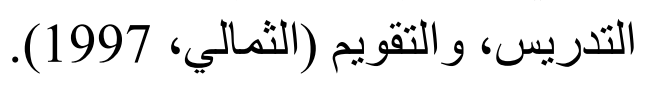

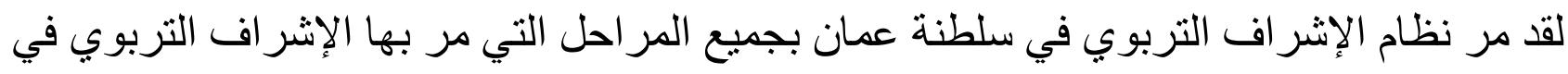
العالم، ففي بدايات السبعينات سادت مرحلة التفنيش التي تميزت بمر اقبة أداء المعلمين، والقيام 


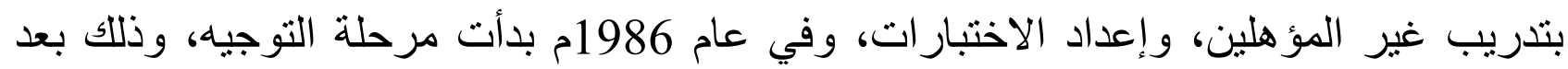

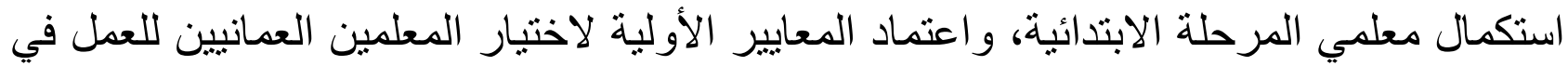

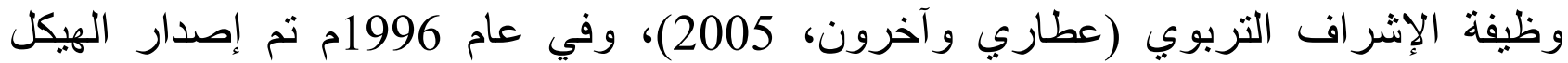

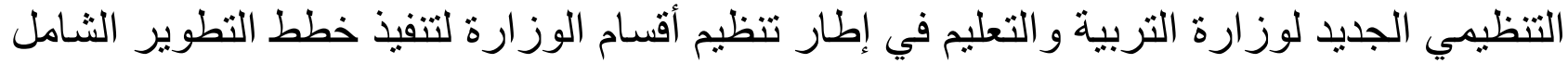

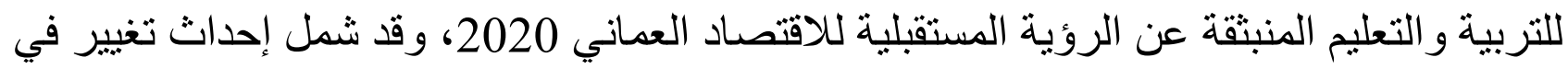

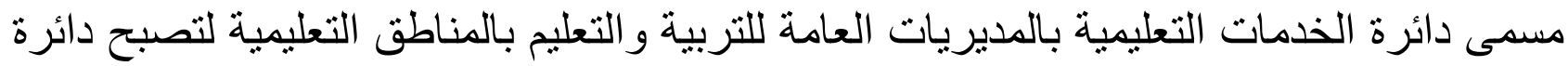

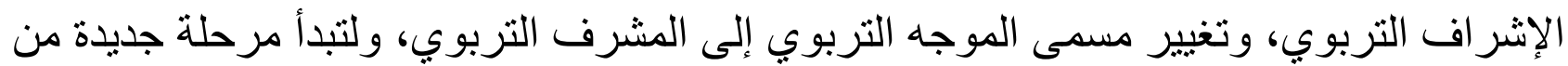
مر احل الإشراف التربوي، كما تم استحداث مسمى المعلم الأول بمدارس التهبئ التعليم الأساسي؛ ليأخذ بعض مهام المشرف التربوي (وزارة التربية و التعليم، 2005). ويؤكد نبر اي (1987) أن ظهور وظيفة المعلم الأول كمشرف تربوي مقيم كان نتيجة لما يعانيه

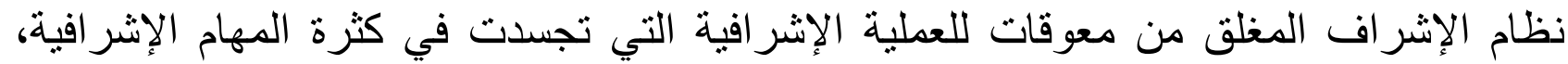

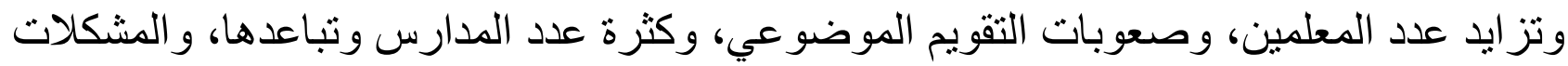

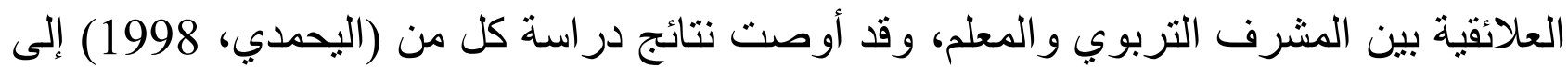

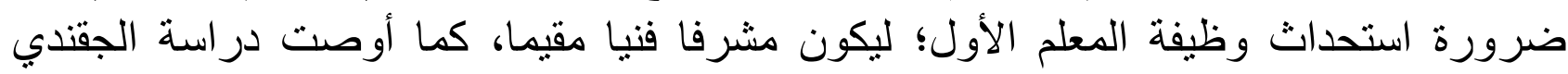

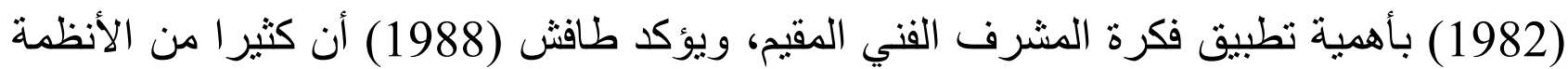
عملت بنظام المعلم الأول لما لهذا النظام من مردود إيجابي على سير العملية التعليمية التعلمية.

و انطلاقا من مرامي الفلسفة التربوية العمانية، وتحقيقا لأهدافها كان لا بد من تطوير العملية

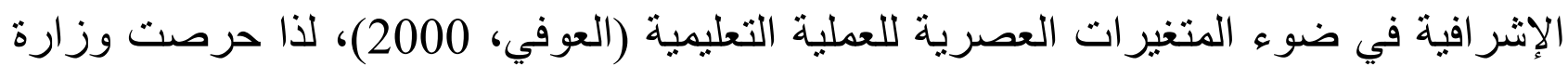

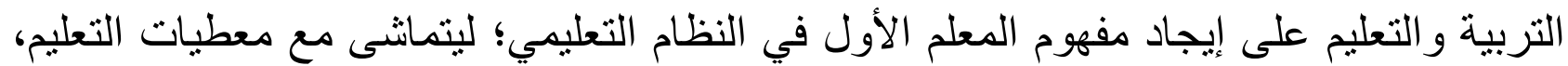

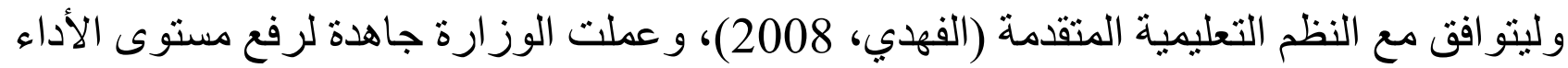

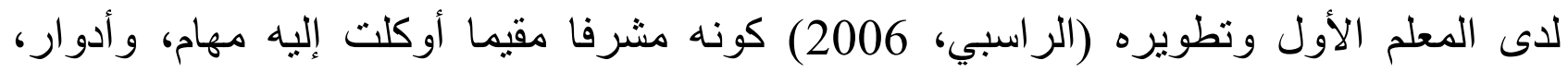

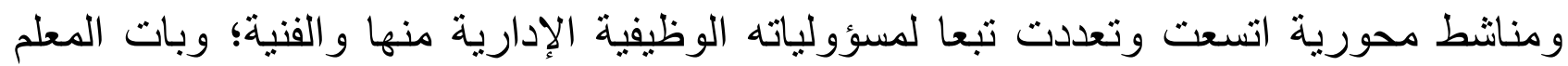

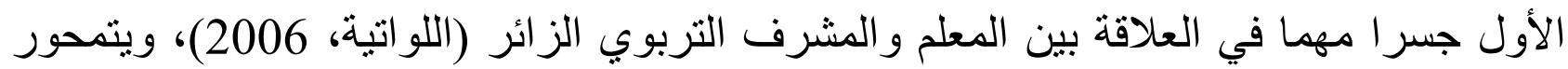

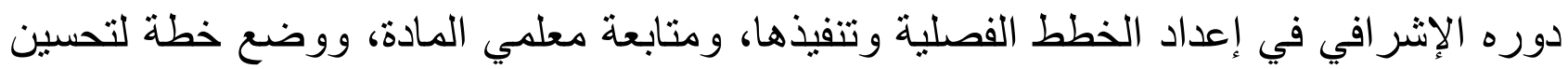

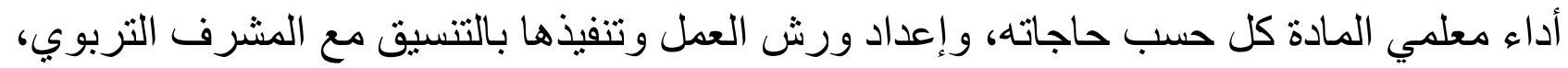

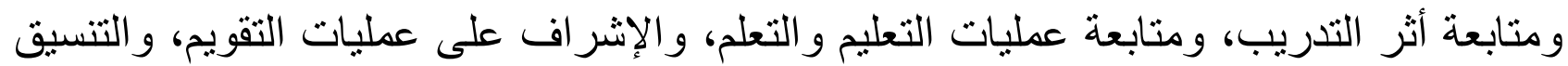

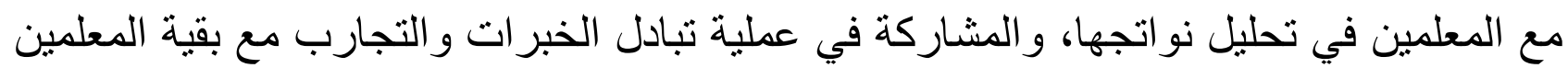

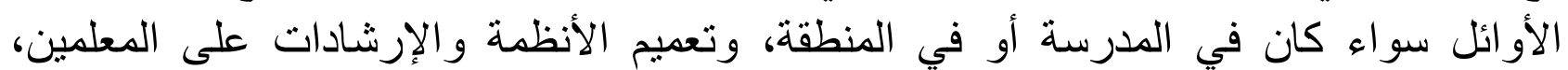

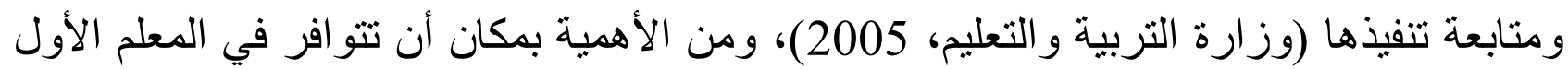

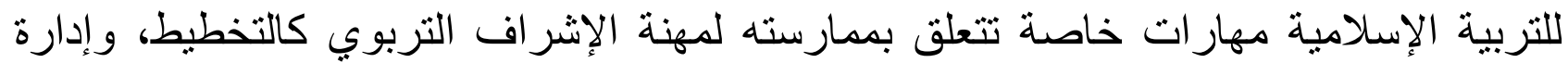

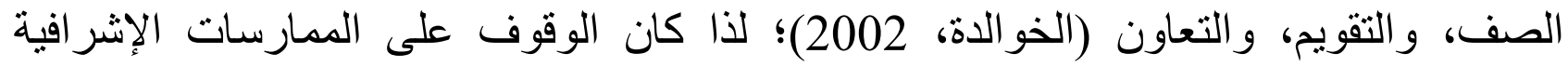
لمعلمي التربية الإسلامية الأو ائل أمر الفوان ملحا. 
مشكلة الار اسة

تسعى وزارة التربية و التعليم في السلطنة لمسايرة التطورات التربوية الحديثة؛ لرفع مستوى العملية التعليمية، وتحسين مخرجاتها، ونظرا لأهمية الإشراف التربوي في تحسين العملية التعليمية التعلمية وتطوير ها، فقد حرصت الوزارة على تفعيل دور الإشراف التربوي، والارتقاء بها، وتطوير ه؛ لإيجاد نظام قادر على تحقيق الأهداف المنشودة.

و من منطلق أن المعلم الأول لكل مادة له اتصال مباشر بالمعلمين مما يمكنه بسهولة وفاعلية من تقديم الدعم لهم وتنمية قدر اتهم المهنية (وزارة التربية والتعليم، 2008)، وتأكيدا لمبدأ الرقابة الذاتية عند المعلم، و الانتماء الفعلي لمهنته (فريق التدريب المركزي، 2008)، و إدر اكا من الوزارة بضرورة زيادة فاعلية الإشر اف التربوي تم تطبيق رؤية المعلم الأول كمشرف مقيم في المدرسة اعتبار ا من العام الدراسي 1999/1998، مما ترتب على ذلك ممارسة المعلم الأول للعديد من المهام و المسؤوليات، ولأن هذا النظام نظاما جديدا يمكن أن ينجم عنه ظهور بعض القصور في ممارساتهم الإشر افية وترجمتها بالصورة المطلوبة، سواء فيما يتعلق بتتفيذ اللائحة التي تحدد المهام الإشر افية، أو و عيهم لتلك المهام، أو درجة امتلاكهم للمهار ات الإشر افية اللازمة لتنفيذ هذا النظام، ناهيك عن الصعوبات والمشكلات التي قد تحد من تلك الممارسات، وقد أشـارت إلى ذلك بعض الدراسات التربوية كدر اسة (المشيفري، 2003؛ الراسبي، 2006؛ المحروقية، 2007؛ القطيطي، 2007)، كما توصلت نتائج دراسة ديكوتي (Duquette, 1994) إلى وجود معوقات في برنامج إعداد المعلم الأول، وتوصلت نتائج در اسة ميل ودارش (Male \& Daresh, 1997) إلى عدم إلمام المعلمين الأوائل بمجالات الممارسات الإشر افية للمعلم الأول ومهامه، و أنهح لم يتلقو ا تدريبا عليها من قبل، لذا يؤكد علي (Ali, 2000) حاجتهم الماسة إلى الدعم و المتابعة و التطوير، ويني الكندي (2003) دراسته للاحتياجات التدريبية للمعلمين الأوائل من منطلق ضعف ممارستهم للمهام الإشر افية.

وبدعم الثعور بالمشكلة خبرة الباحث في الميدان التربوي كمشرف تربوي لمادة التربية الإسلامية، ومشاركاته في لجان تقييم المعلمين الأوائل في منطقة الباطنة شمال، وملاحظة أن ممارسات بعض معلمي التربية الإسلامية الأوائل لمهامهم الإشر افية تحتاج إلى مزيد من الدراسة

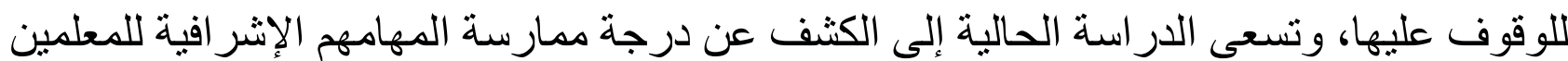
الأوائل، من خلال استطلاع آراء معلمي التربية الإسلامية الذين بشرفون عليهم، وآراء مديري المدارس؛ لإبراز الدور الإشر افي في العملية التعليمبة.

أهداف الدراسة: الهدف الرئيس للدر اسة هو: تشخيص درجة ممارسة معلمي التربية الإسلامية الأوائل لمهامهم الإشر افية من وجهة نظر مديري المدارس ومعلمي المادة. ويتفرع عن هذا الهدف؛ الأهداف الفر عية الآتية: 


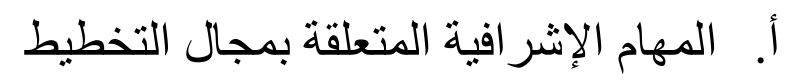

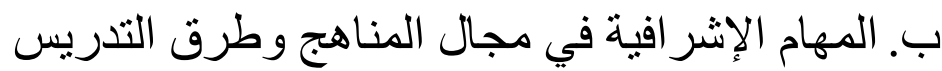

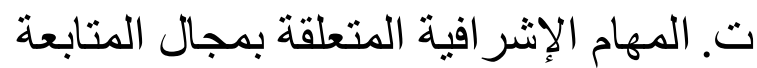

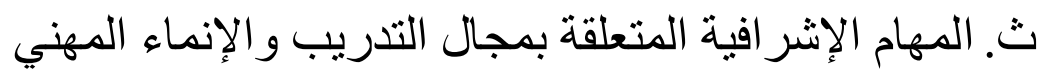
ج. مجال العلاقات الإنسانية و المجتمع المحلي.

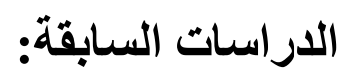

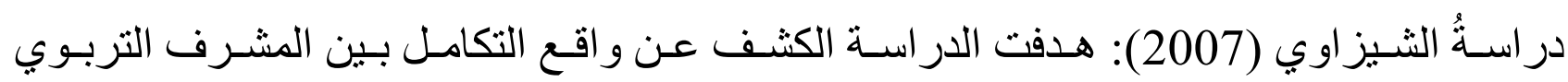

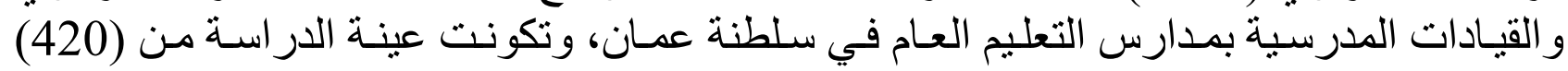

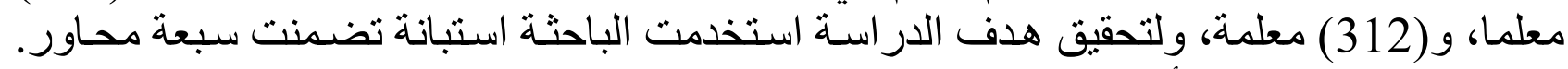

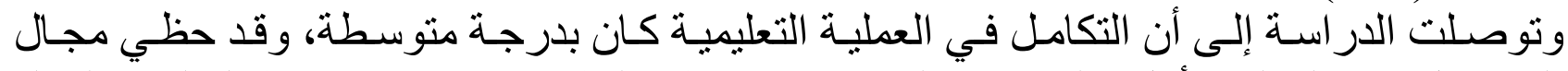

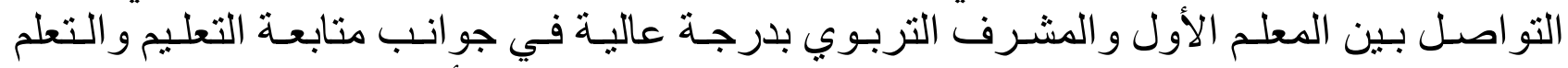

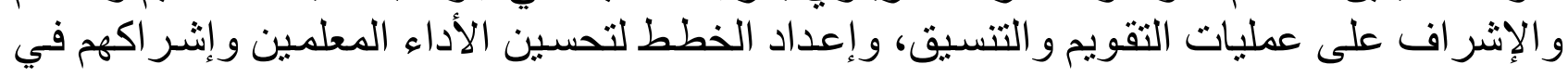
الدورات التدريبية وتبادل الخبرات، وتحديد احتياجاتهم ومتابعتها.

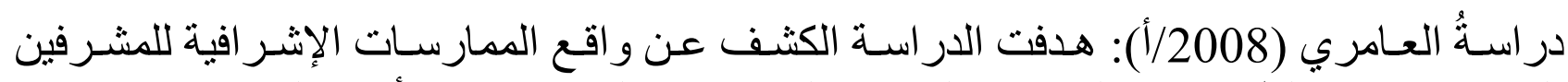

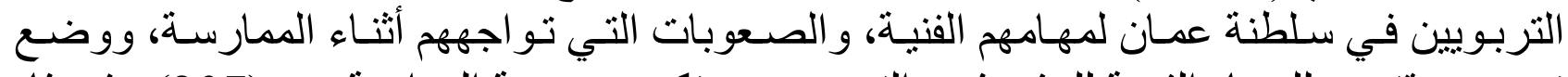

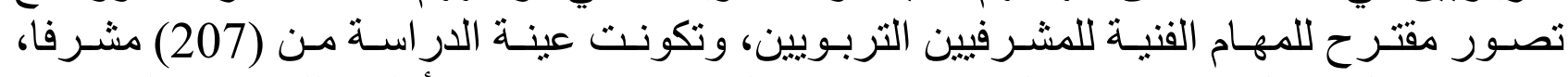

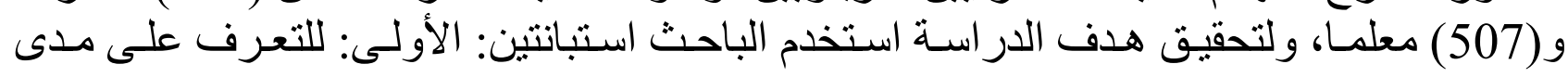

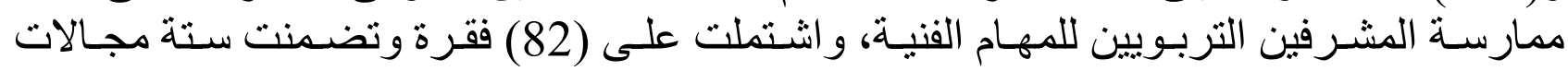

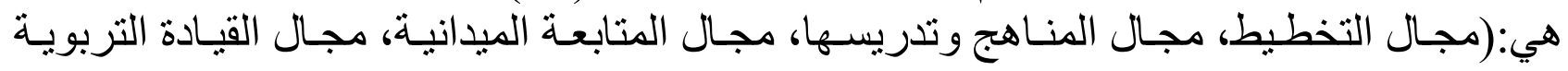

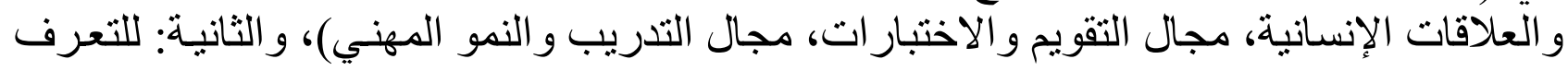

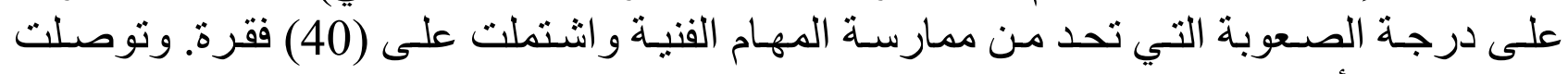

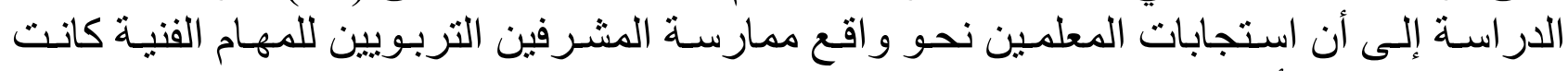

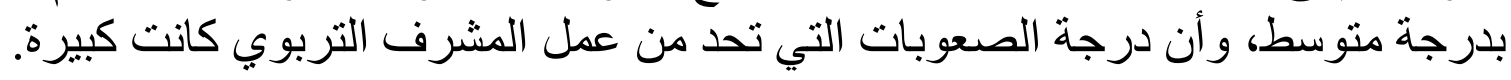

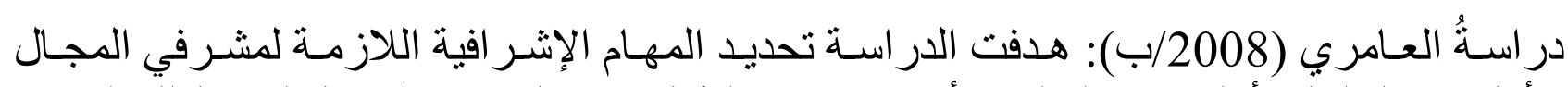

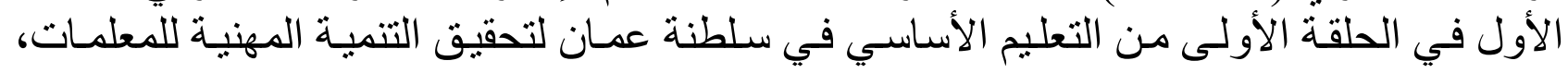

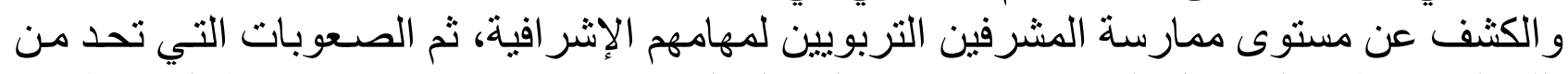

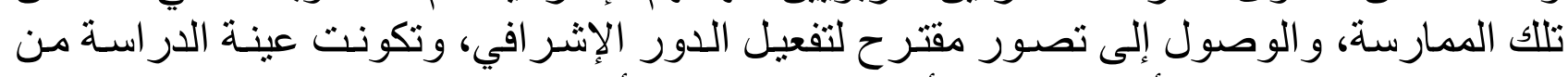

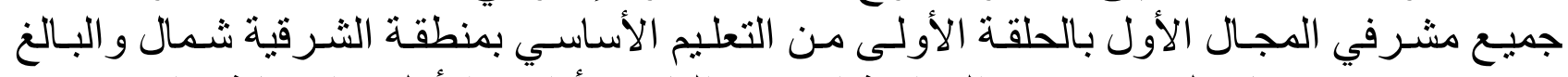

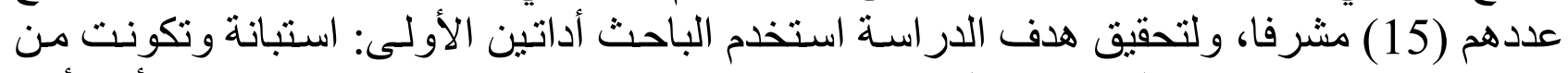

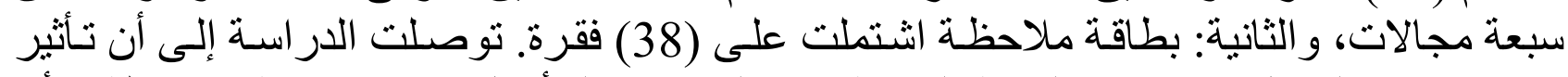

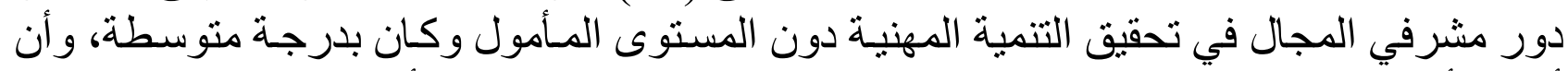

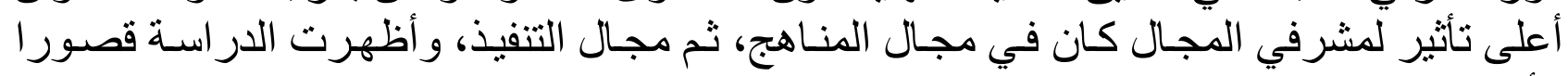

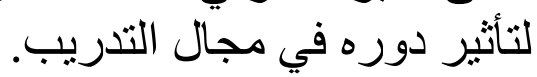




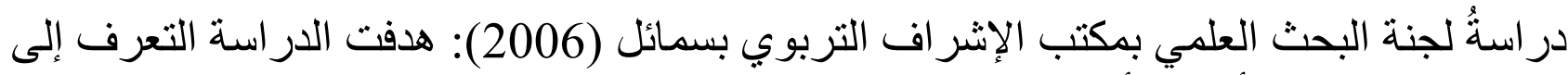

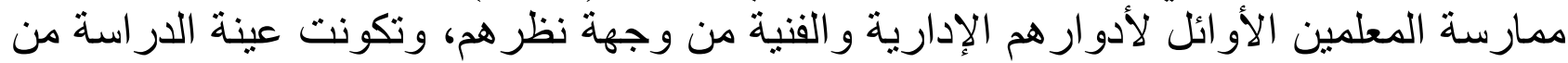

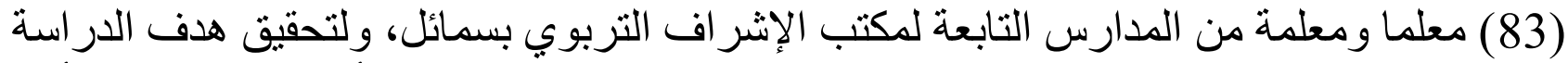

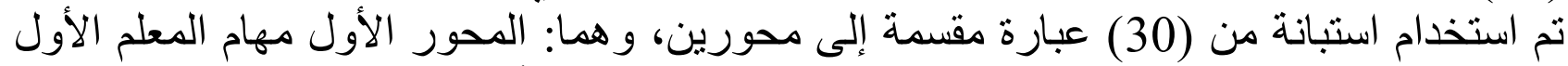

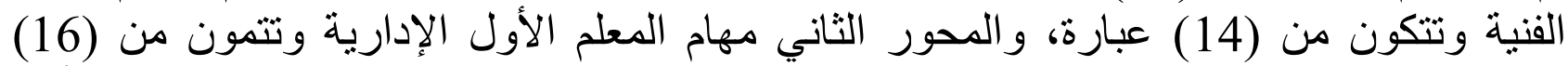

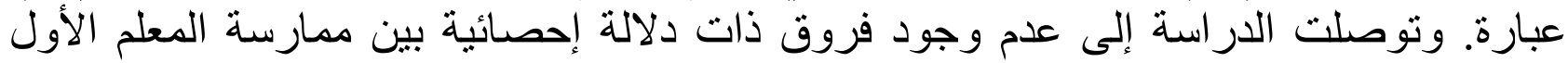

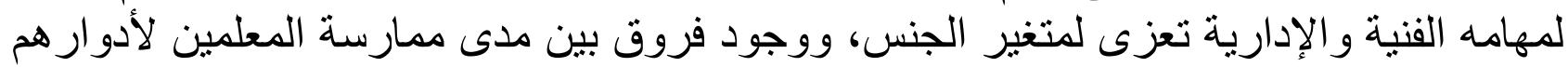

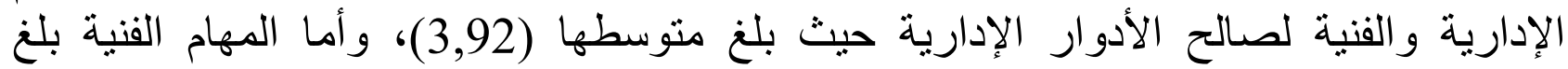

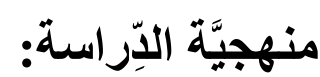

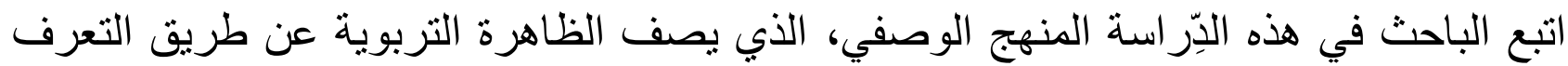

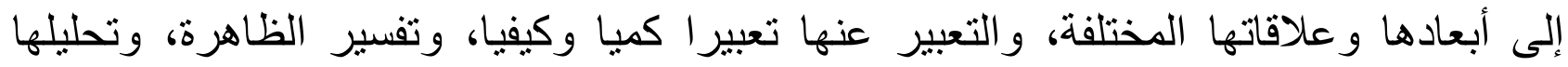

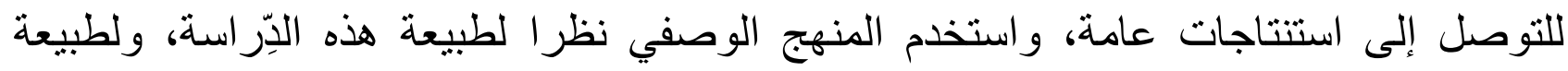
البيانات المر اد الحصول عليها. مجتمع الاراسة: فئة مديري المدارس: تكونت من جميع مديري المدارس الحكومية في الحلقة الثانية من التعليم

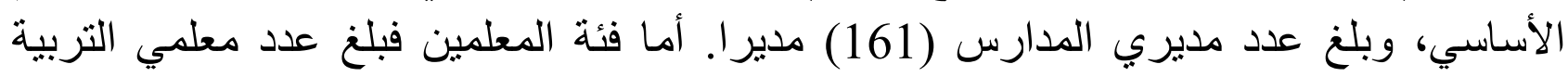
الإسلامية (849) معلما.

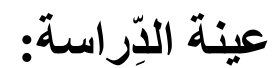

بلغتنْ عينة مديري المدارس (80)، و عدد عينة معلمي التربية الإسلامية (170) معلما ومعلمة.

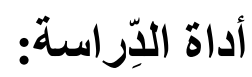
قام الباحث بتصميم استبانة وفق مقياس ليكرت الخماسي، بعد أنْ أعدّ قائمة بالمهام الإشر افية لمعلم

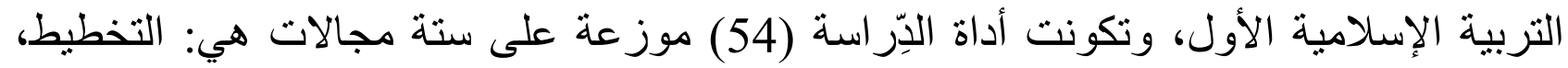

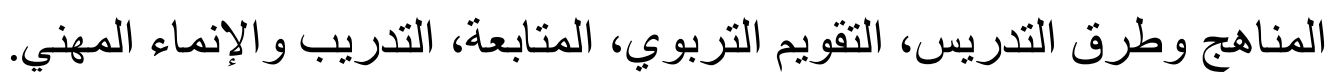

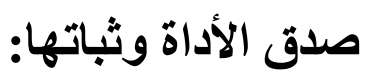

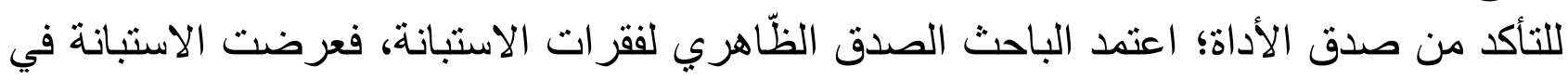

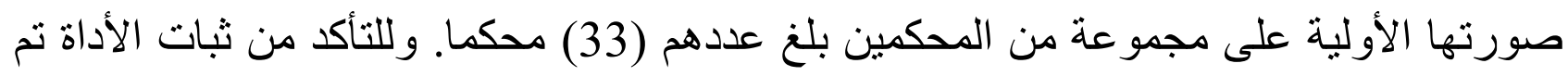

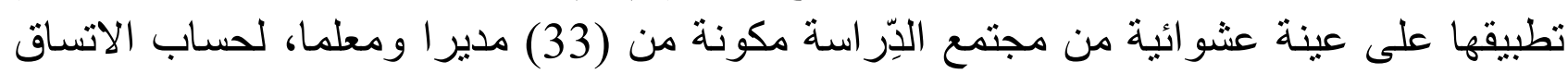

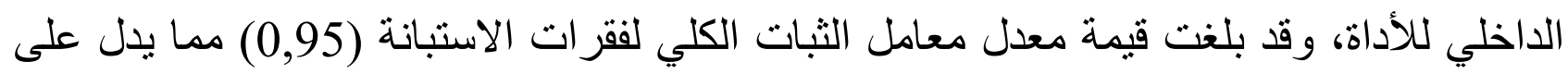

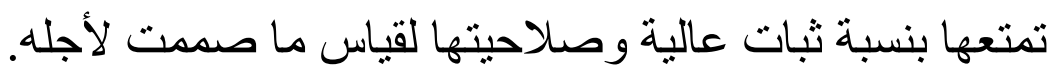

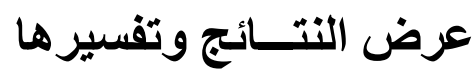

النتائج المتعلقة بالسؤال الرئيس: "ما درجة ممارسة معلمي التربية الإسلامية الأوائل لمهامهم

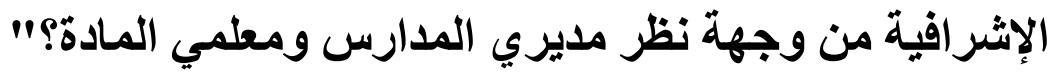


للإجابة عن هذا السؤال تم استخر اج المتوسطات الحسابية والانحر افات المعيارية لكل المهام

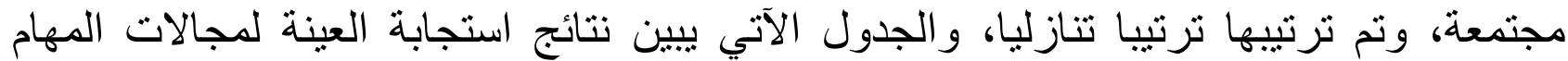

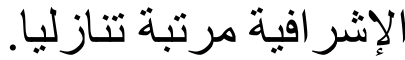

الجدول (1) المتوسطات الحسابية والانحر افات المعيارية لمجالات المهام الإشر افية مرتبة تنازليا

\begin{tabular}{|c|c|c|c|}
\hline درجة الممارسة & الالحعياري & المتوسط الحسابي & 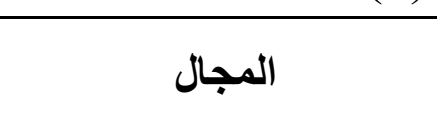 \\
\hline كبيرة جدا & 0,51 & 4,36 & العلاقات الإنسانية والمجتمع \\
\hline كبيرة & 0,64 & 4.03 & المتابعة المبدانية \\
\hline كبيرة & 0,65 & 4,02 & التخطيط \\
\hline كبيرة & 0,65 & 3,91 & التقويم التربوي \\
\hline كبيرة & 0,74 & 3,80 & المناهج وطرق التدريس \\
\hline كبيرة & 0,81 & 3,55 & التدريب و الإنماء المهني \\
\hline كبيرة & 0,67 & 3,95 & معدل المجالات الستة \\
\hline
\end{tabular}

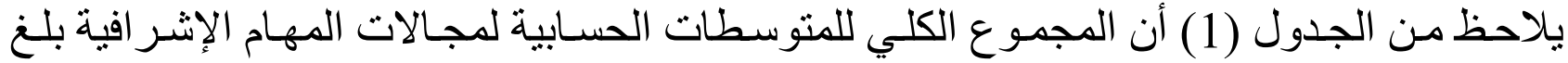

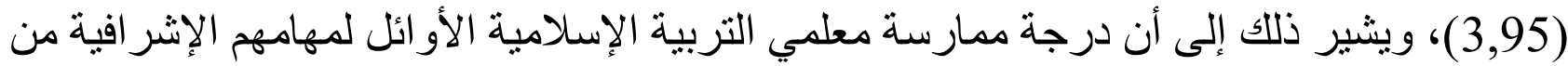

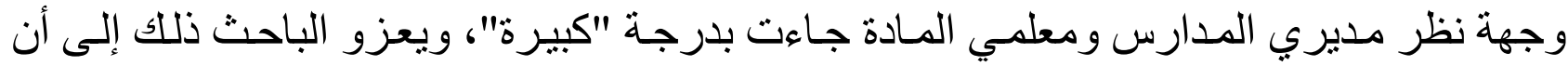

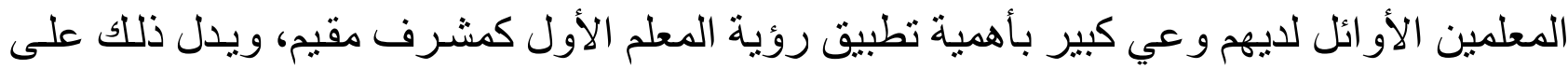

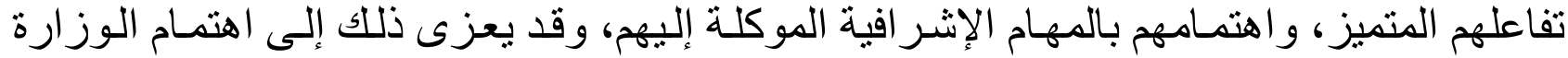

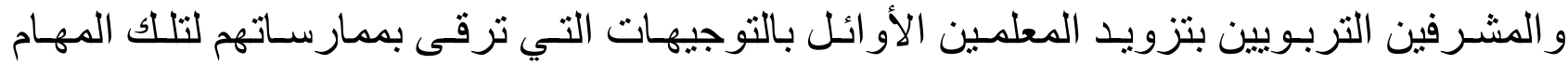

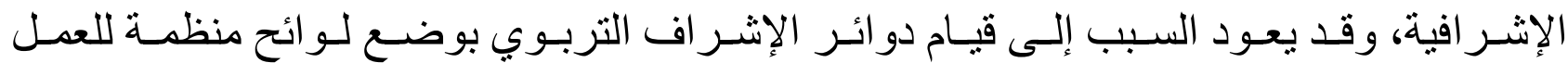
الإنشر افي.

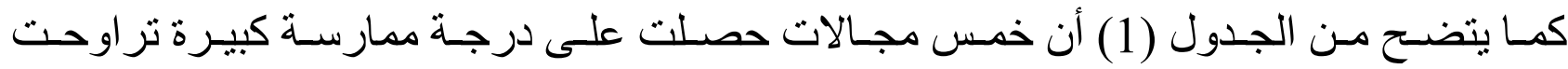

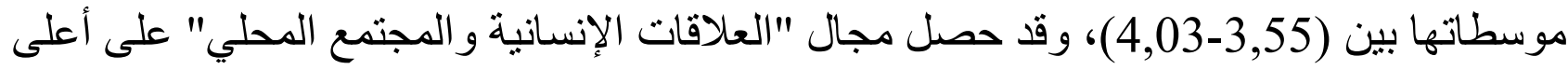

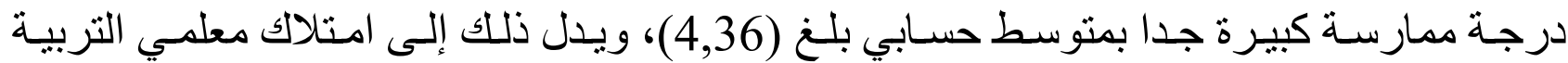

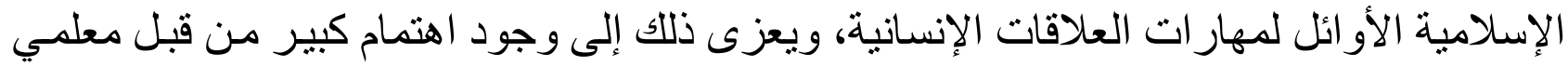

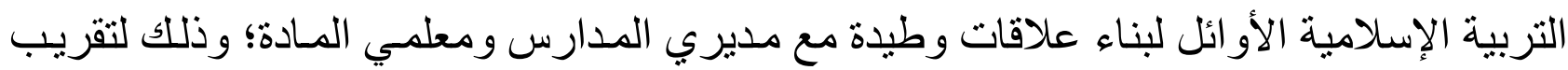

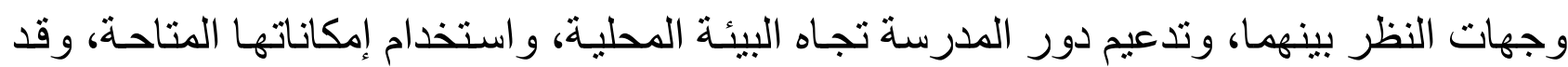

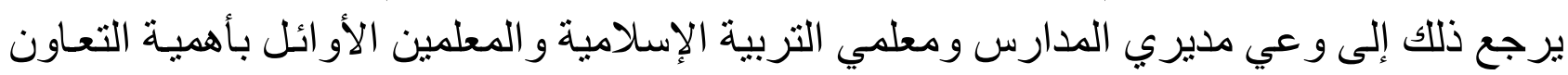

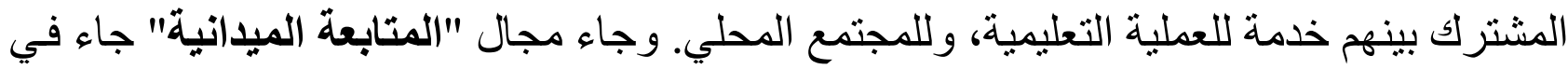

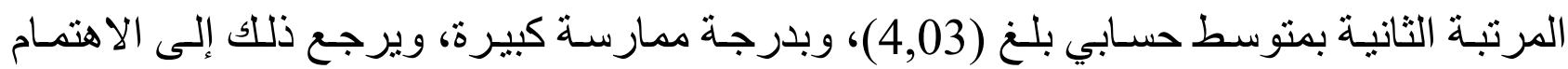

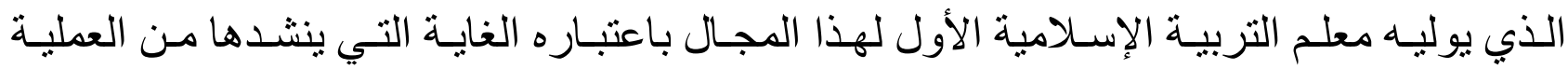

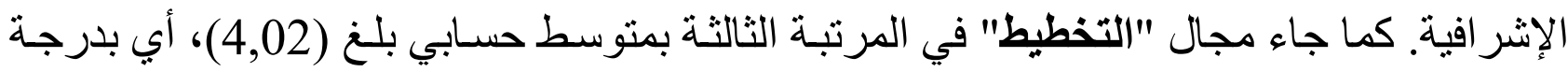


ممارسة كبيرة، ويعزى ذلك إلى إدر الك معلمي التربية الإسلامية الأوائل لأهمية التخطبط في تتظيم

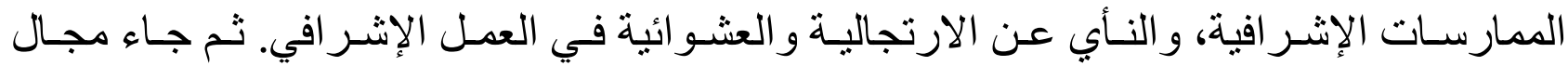

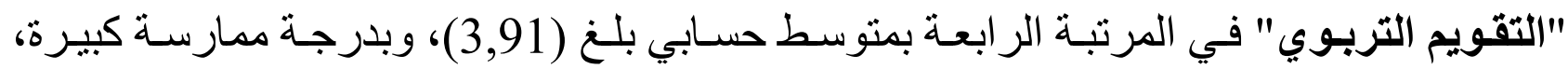

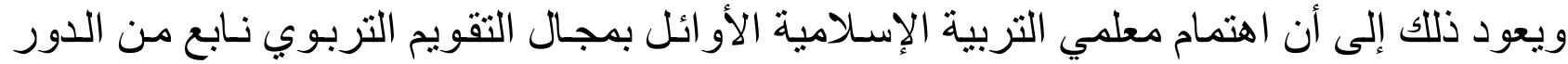

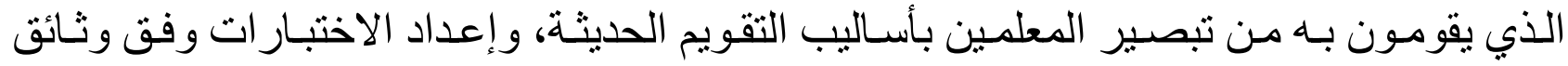

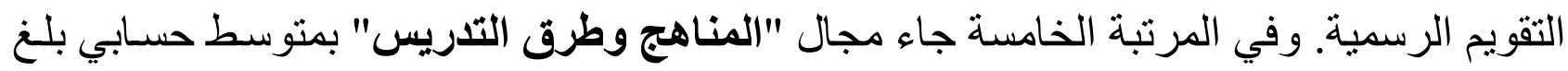

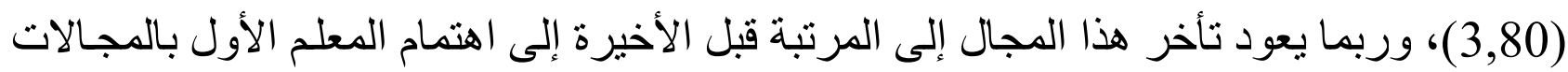

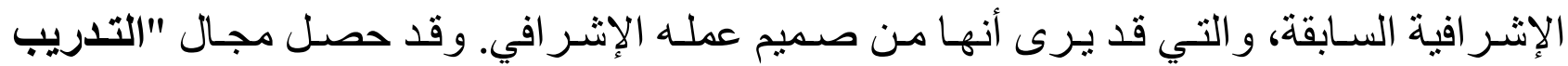

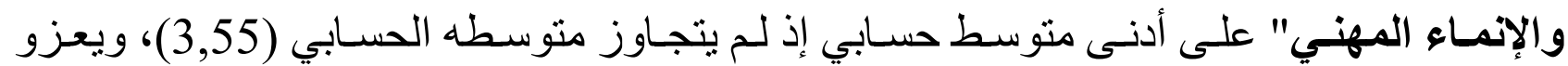

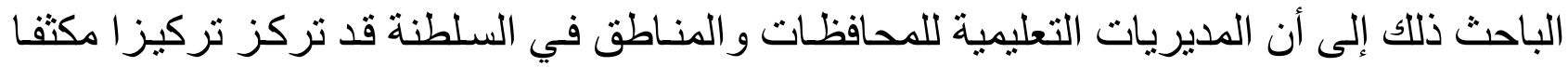

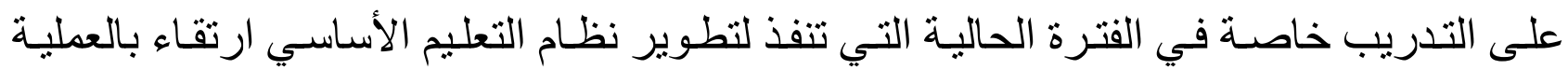
التعليمية التعلمية.

تتفق هذه النتيجة مـع نتائج در اسـة العوفي (2000) التي توصلت إلى أن درجـة ممارسـة أنشطة

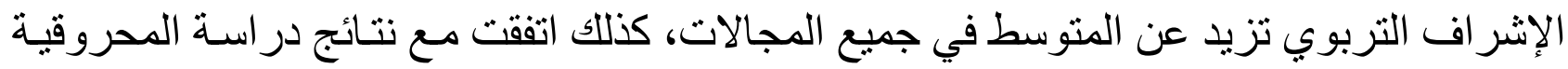

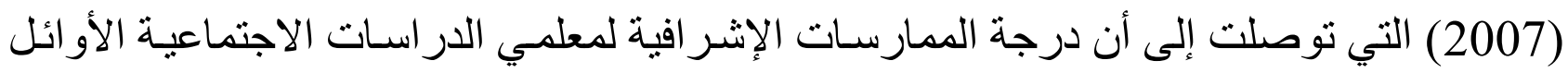

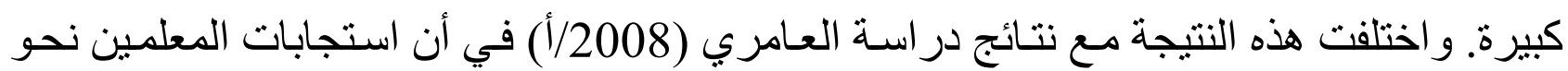

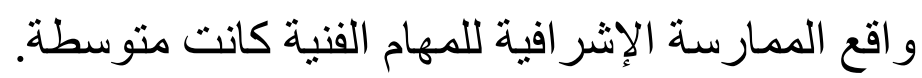

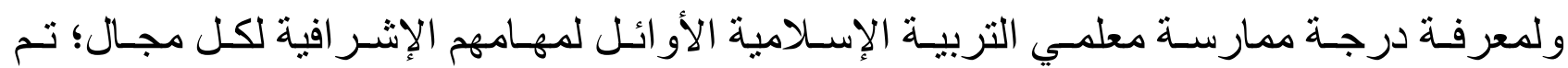

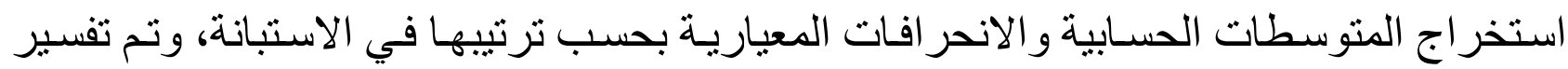

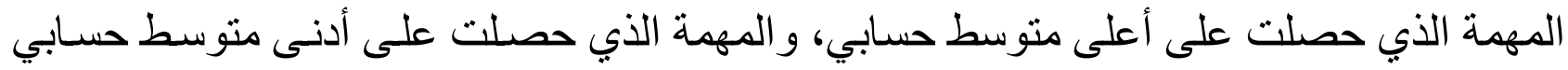
في كل مجال من المجالات، وذلك على التى النحو الآتي:

\section{المجال الأول: التخطيط}

يبين الجدول الآتي نتائج استجابة العينة للمهام الإشر افية المتعلقة بمجال التخطيط مرتبة تنازليا.

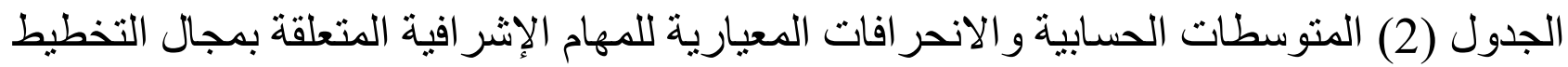

\begin{tabular}{|c|c|c|c|c|}
\hline المارسة & المعياري & المتوسط & المهــــــــام & 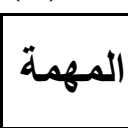 \\
\hline كبيرة & 0.77 & 4.51 & يضع خطة لزيارة المعلمين في صفوفهم. & 4 \\
\hline كبيرة & 0.88 & 4.30 & 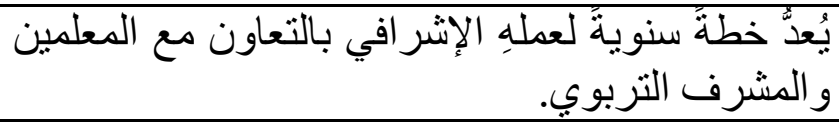 & 1 \\
\hline كبيرة & 0.91 & 4.26 & يضع خططا لتبادل الزيار ات بين المعلمين. & 5 \\
\hline
\end{tabular}




\begin{tabular}{|c|c|c|c|c|}
\hline 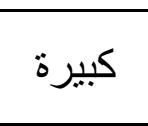 & 1.00 & 4.13 & يشّارك في وضرف المسابقة و المعة لمسابقة القرآن الكريم بالتعاون & 6 \\
\hline كبيرة & 0.84 & 4.04 & المشرف خطظ التربوي. لإنماء المعلمين مهنيا بالتعاون مع & 2 \\
\hline كبيرة & 0.97 & 4.04 & يتعاون مع المعلمين في إعداد الخطط التدريسية. & 3 \\
\hline كبيرة & 1.04 & 3.90 & مُع المعدُ خططين علاجية لر المعاية الطلبة المتأخرين بالتعاون & 9 \\
\hline كبيرة & 1.03 & 3.70 & 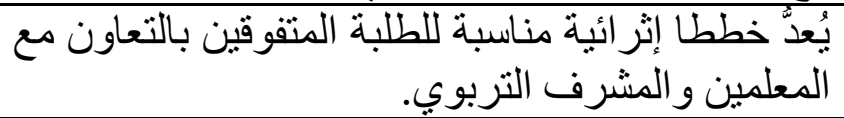 & 8 \\
\hline 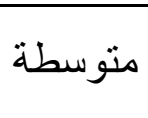 & 1.11 & 3.33 & مصتعادر التعلم بصورة المعلمين لإعداد خطظة لزيارة مركز & 7 \\
\hline كبيرة & 0.65 & 4.02 & معدل مجال التخطيط & \\
\hline
\end{tabular}

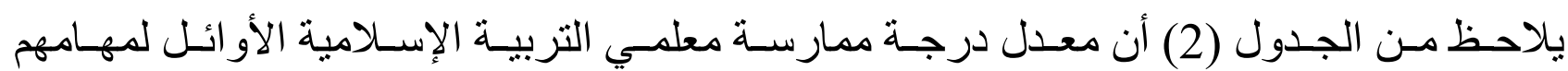

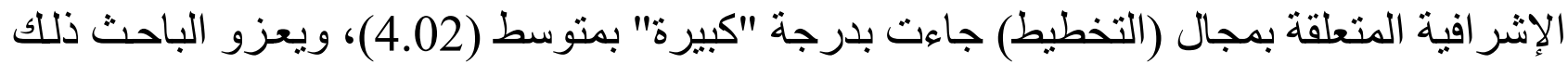

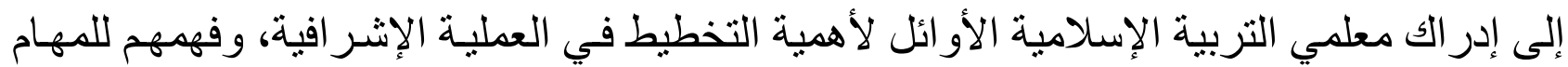
المتعلقة بمجال التخطيط، و إلمامهم الجيد بالخطط التي يتضندها هذا المجال، وقد يعود السبب إلى الصى

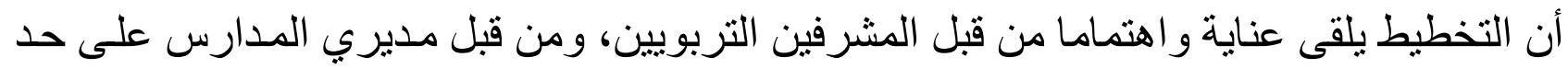

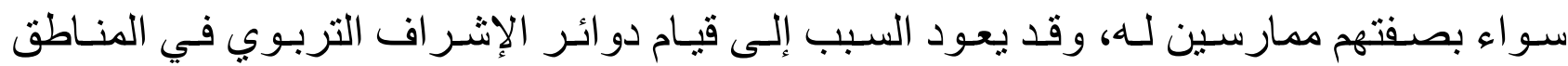
التعليمية بوضع لو ائح منظمة لممارسة العمل الإشر افي.

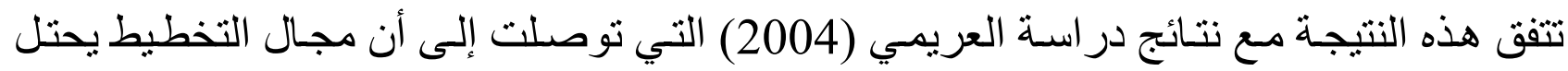

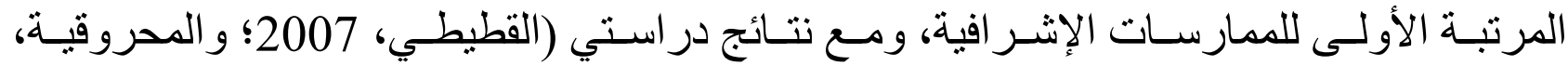

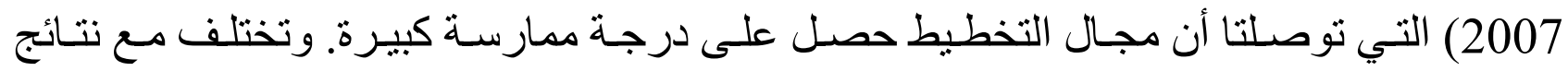
در اسة (العامري، 2008/ب) التي أثنارت إلى أن الممارسات الإشر افية في مجال التخطيط كانت دئت بدرجة متوسطة.

ويتضح من الجدول (2) أن المتوسطات الحسابية لمهام هذا المجال تراوحت بين (4,51-3,33)،

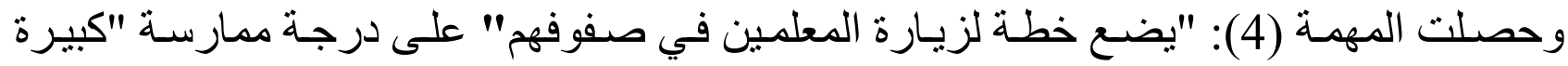

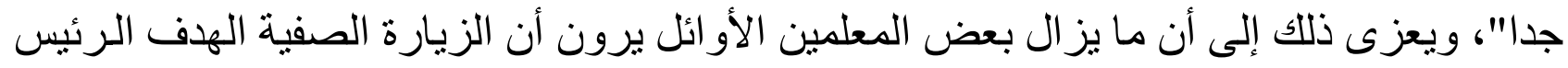

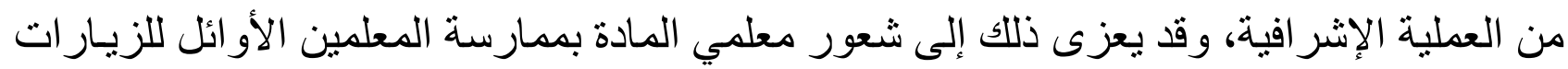

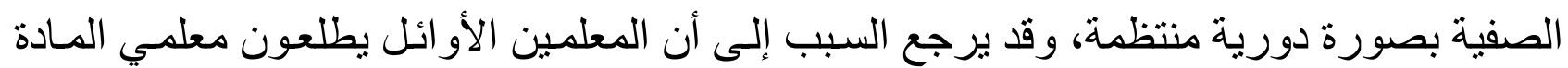

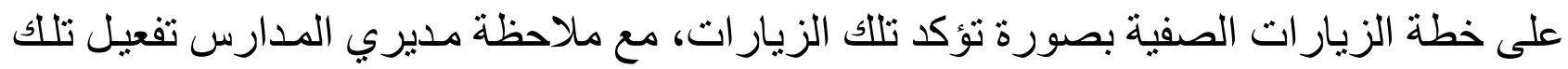

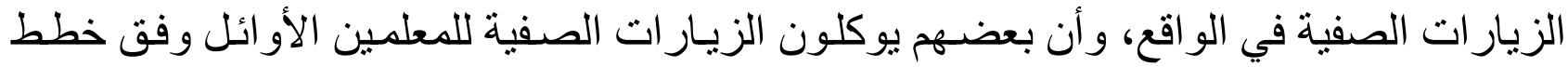

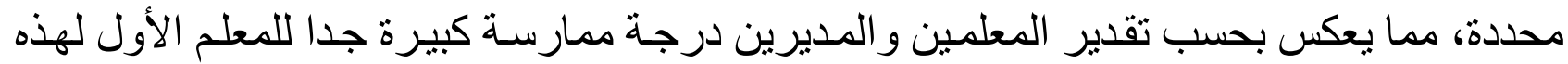


وحصلت المهمة (7): " يتعاون مـع المعلمين لإعداد خطط لزيسارة مركز مصسادر التعلم بصورة

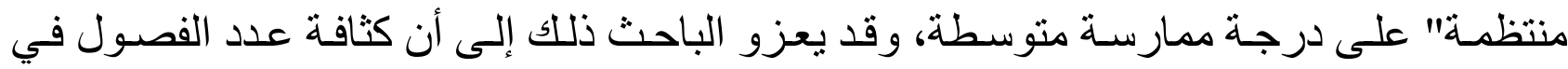

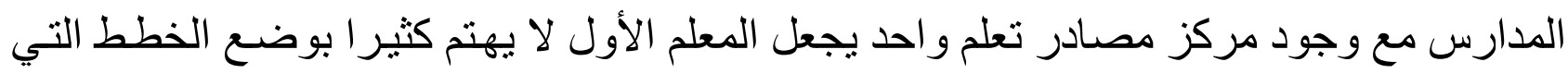
لا يمكن تطبيقها في الو اقع. وقد حصلت باقي المهام في هذا المجال على درجة ممارسة كبيرة.

\section{المجال الثاني: مجال المناهج وطرق التدريس:}

يبين الجدول الآتي نتائج استجابة العينة للمهام الإشـر افية المتعلقة بمجال المنـاهج وطرق التدريس مرتبة تناز ليا.

الجدول (3) المهام الإشر افية المتعلقة بمجال المناهج وطرق التدريس مرتبة تنازليا

\begin{tabular}{|c|c|c|c|c|}
\hline 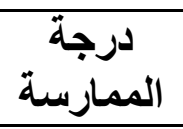 & المعياري & المتوسط & المهـــــــام & 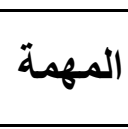 \\
\hline كبيرة جدا & 0,85 & 4,26 & الخديثة. المعلمين على استخدام استراتيجيات التدريس & 17 \\
\hline كبيرة جدا & 0,87 & 4,24 & يحث المعلمين على توظيف التقانات الحديثة في التدريس. & 16 \\
\hline كبيرة & 0,91 & 4,14 & المعاصهرة. المعلمين إلى ربط المناهج بحياة الطلبة وحاجاتهم & 15 \\
\hline كبيرة & 1,00 & 3,93 & يناقش مع المعلمين عناصر منهاج التربية الإسلامية. & 10 \\
\hline كبيرة & 1,05 & 3,78 & يتعاونة مع المعاهجين لتصميم أنشطة صفية وغير صفية & 18 \\
\hline كبيرة & 1,07 & 3,51 & يقتر ح آليات لتطوير مناهج التربية الإسلامية. & 13 \\
\hline كبيرة & 1,07 & 3,50 & بالمناهج اللأخرى. لمعين كيفية ربط مناهج التربية الإسلامية & 14 \\
\hline كبيرة & 1,10 & 3,43 & يشارك لالمعلمين في تحليل المناهج الدراسية. & 12 \\
\hline متوسطة & 1,10 & 3,36 & يشرح للمعلمين كيفية نقد المناهج نقدا بناء. & 11 \\
\hline كبيرة & $\mathbf{0 , 7 4}$ & $\mathbf{3 , 8 0}$ & معدل مجال المناهج وطرق التدريس & \\
\hline
\end{tabular}

يلاحظظ مـن الجدول (3) أن معـدل درجـة ممارسـة معلمـي التربيـة الإسـلامية الأو ائـل لمهـامهم

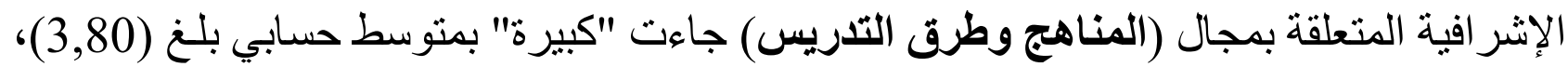

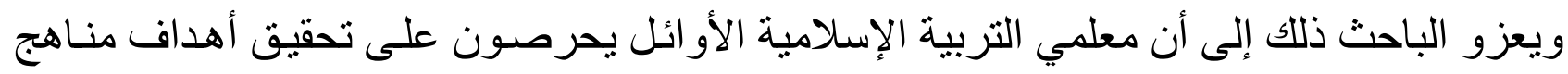

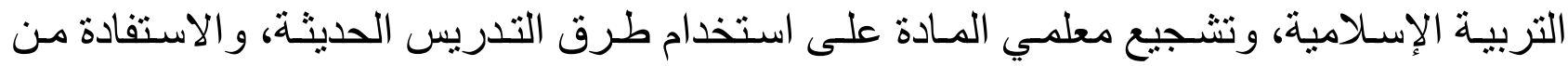

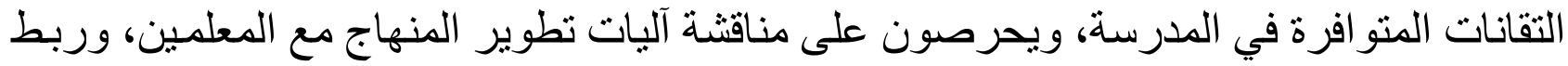

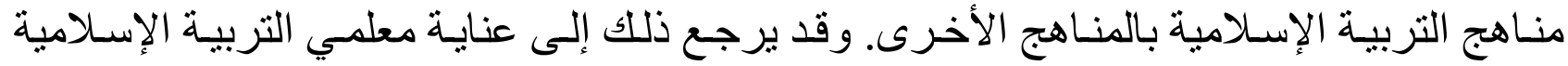

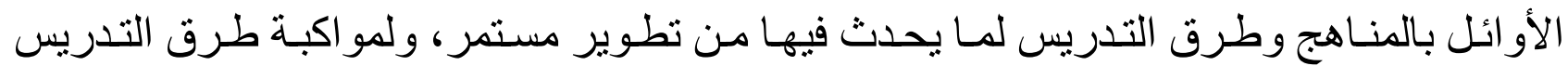
الحديثة، إضافة إلى قيامهم بالتدريس الفعلي لتلك المناهج. 


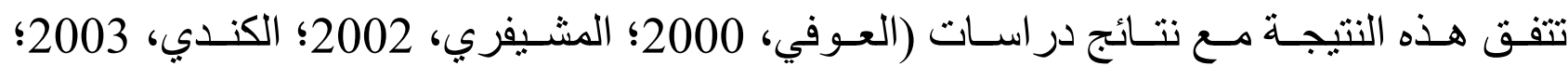
العامري، 2008/ب) التي أكدت أن مجال المناهج وطرق التدريس من أعلى التهى المجالات الإشر افية للمشرف التربوي.

ويتضح من الجدول أعلاه أن المتوسطات الحسابية لمهام مجال المنـاهج وطرق التدريس تر اوحت بين (4,26-3,36)، وحصلت المهمة (17): " يشجع المعلمين على استخدام استر اتيجيات التدريس الهيس

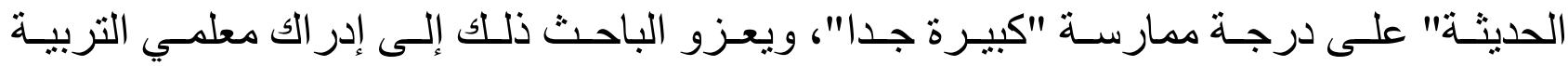

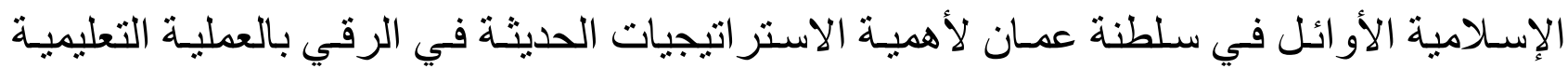

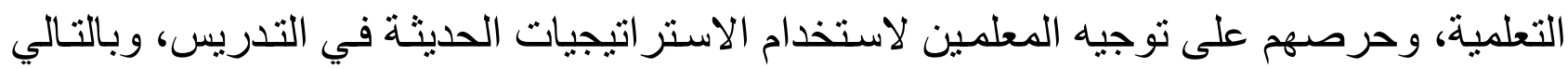

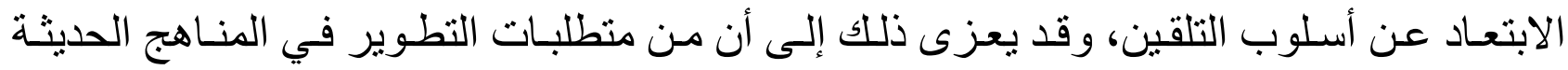

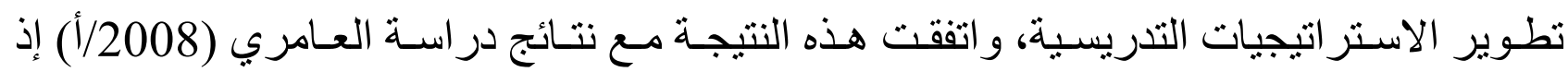

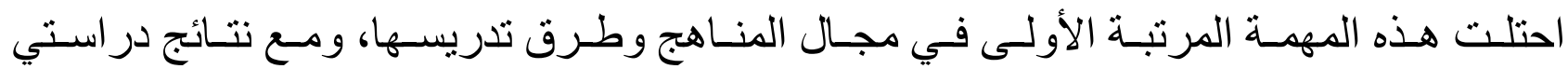
(الخياري، 2002؛ الكندي، 2003) إذ حصلت هذه المهمة على دلى درجة ممارسة كبيرة،

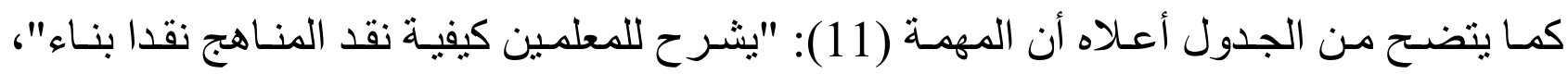

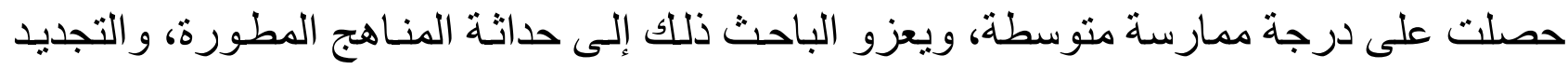

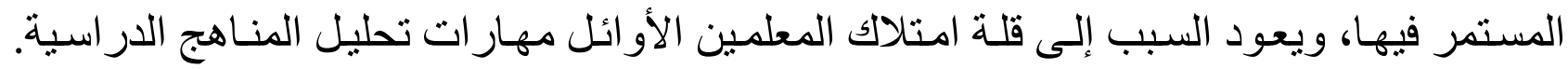
تتفق هذه النتيجة مع نتائج در اسة الخياري (2002)، وتختلف مئف مع نتائج در اسة المحروقيـة (2007) حين حصلت على درجة ممارسة كبيرة.

المجال الثالث: مجال التقويم التربوي يبين الجدول الآتي نتائج استجابة العينة للمهام الإشر افية المتعلقة بمجال التقويم التربوي مرتبة تنازليا.

الجدول (4) للمهام الإشر افية المتعلقة بمجال التقويم التربوي مرتبة تنازليا

\begin{tabular}{|c|c|c|c|c|}
\hline الممارجة & الانحراف المعياري & المتوسط الحسبي & المهـــــــام & المهمة \\
\hline كبيرة & 0,86 & 4,24 & يطلع المعلمين على مستجدات التقويم التربوي. & 19 \\
\hline كبيرة & 0,86 & 4,22 & يقوّم أداء المعلمين بصورة دورية. & 27 \\
\hline 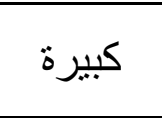 & 0,95 & 4,05 & يقوم بمتابعة ملفات أعمال الطلبة، ومستويات & 23 \\
\hline 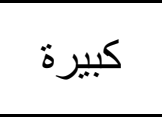 & 0,79 & 4,03 & الحديثة. المعلمين على اكتساب مهار ات التقويم & 20 \\
\hline كبيرة & 0.88 & 3,89 & يقوّم أدوات التقويم المستخدمة في التدريس. & 24 \\
\hline 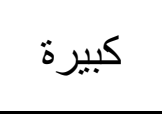 & 0,84 & 3,88 & المعلمين. لاستخدام مفهوم أسلوب التقويم الذاتي مع & 26 \\
\hline
\end{tabular}




\begin{tabular}{|c|c|c|c|c|}
\hline 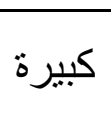 & 0,84 & 3,80 & يوظلف نتائج أدوات التقويم لتحسين مستوى أداء & 25 \\
\hline كبيرة & 1,02 & 3,70 & يشارك المعلمين في إعداد أدوات التقويم. & 21 \\
\hline 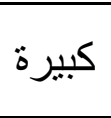 & 1,03 & 3,41 & أدوات التقونيم. مع المعلمين لتحليل النتائج المستخلصة من & 22 \\
\hline كبيرة & 0,65 & 3,91 & معدل مجال التقويم التربوي & \\
\hline
\end{tabular}

يلاحظ مـن الجدول (4) أن درجـة ممارسـة معلمي التربيـة الإسـلامية الأوائل لمهامهم الإشـر افية

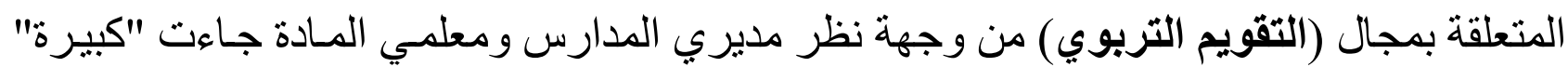

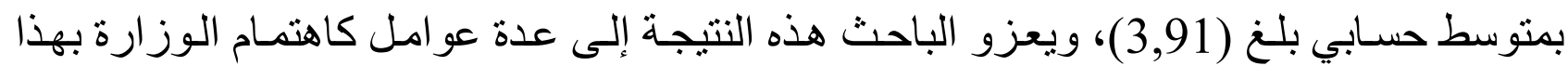

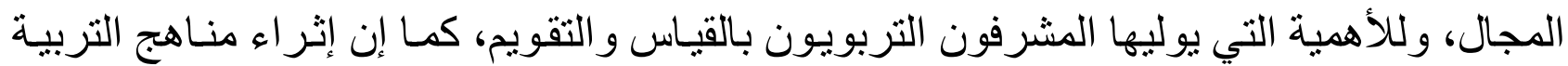

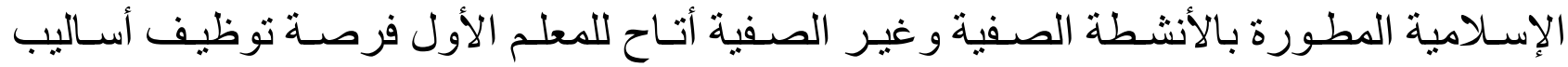
التقويم التربوي.

تتفق هذه النتيجة مع نتائج الدر اسات الآتية: در اسة المشيفري (2002) التي أثنارت إلى أن مجال التيال

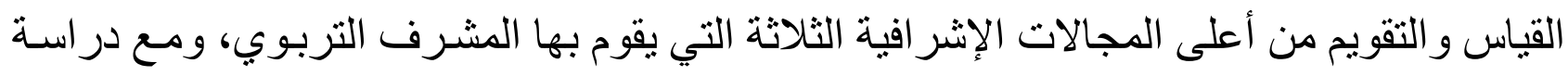
المحروقية (2007) التي جاء فيها مجال التقويم في المرتبة الثانية، ومع در اسة كل من (القطيطي، التئية

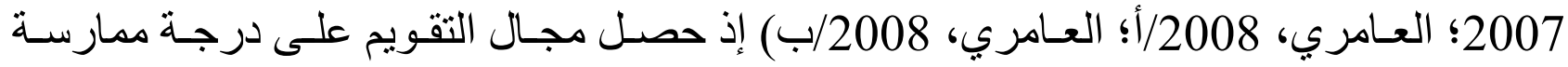

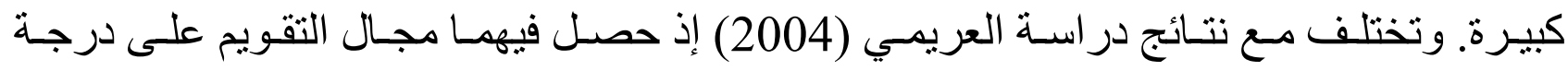

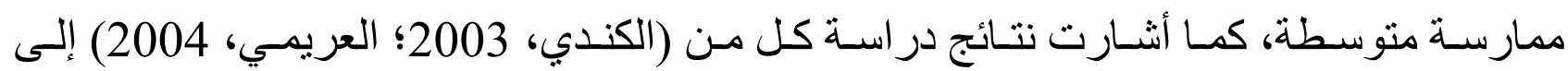
الحاجة التدريبية و عدم تمكن المعلمين الأوائل في مجال التقويم. دئل

ويتضح من الجدول أعلاه أن المتوسطات الحسابية لمهام مجال التقويم التربوي نراوحت بين

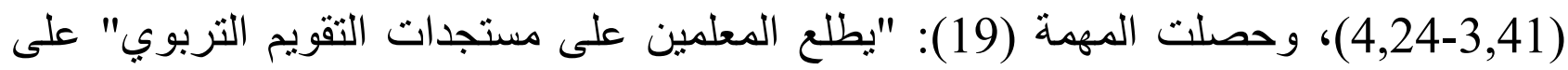

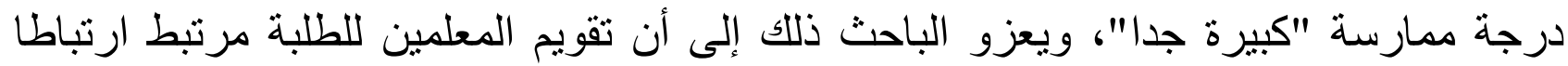

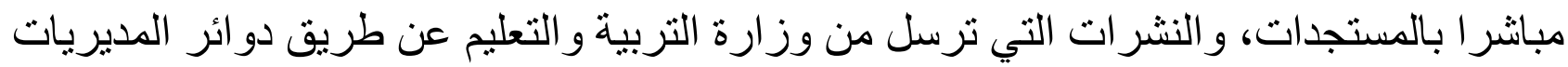

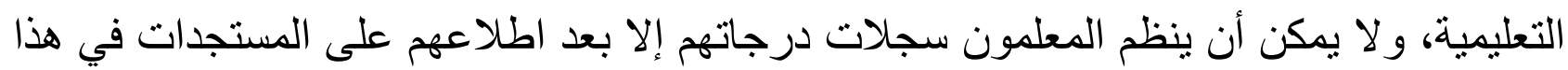

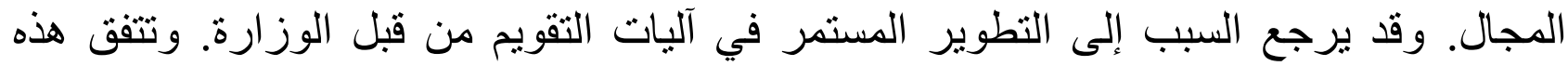

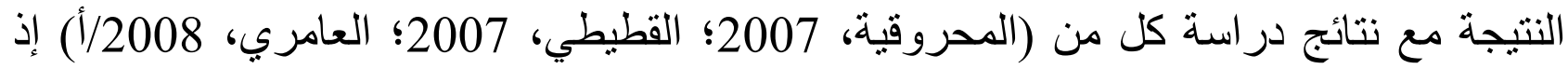

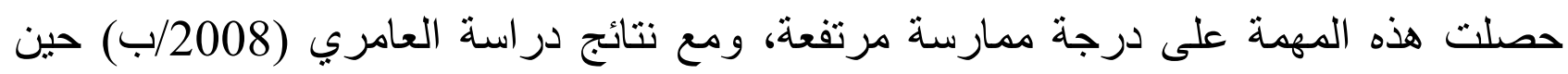

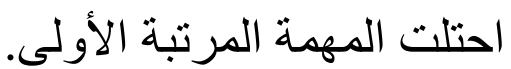

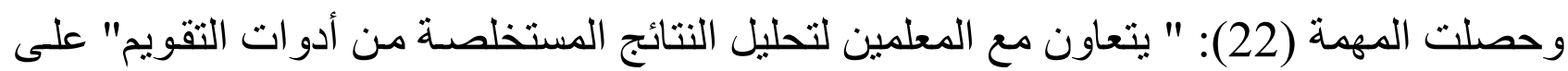

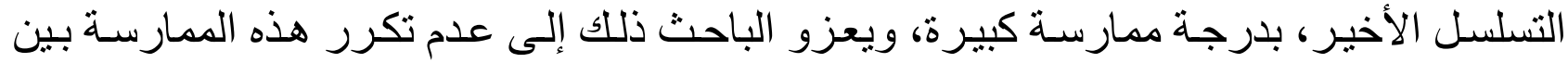

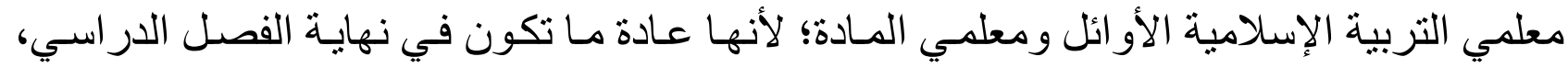
وقد يرجع سبب ذللك إلى عدم شعور المعلمين الأو ائل بأهمية عملية تحليل النتائج. 


\section{المجال الرابع: مجال المتابعة الميدانية:}

يبين الجدول الآتي نتائج استجابة العينة للمهام الإثر افية المتعلقة بمجـال المتابعة الميدانية مرتبـة تنازليا.

الجدول (5) المهام الإشر افية المتعلقة بمجال المتابعة الميدانية ترتيبا تتازليا

\begin{tabular}{|c|c|c|c|c|}
\hline الممارسة & المعياري & المسابي & المهــــــــام & 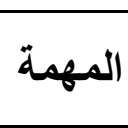 \\
\hline كبيرة & 0,78 & 4,42 & بطلع على دفاتر تحضير المعلمين وسجلاتهم. & 30 \\
\hline كبيرة & 0,80 & 4,35 & يقوم بزيار ات صفية كافية. & 28 \\
\hline كبيرة & 0,84 & 4,28 & يعقد لقاءات دورية مع المعلمين. & 31 \\
\hline كبيرة & 0,83 & 4,26 & المعدة. تنفيذ المعلمين للمناهج الدراسية وفق الخطط & 34 \\
\hline كبيرة & 0,86 & 4,08 & الإسلامية في المدرسة. متابعة الأنشطة الدصاحبة للتربية & 33 \\
\hline كبيرة & 0,92 & 3,92 & يتابع الملحوظات الفنية لتقليم تغذية راجعة للمعلمين. & 35 \\
\hline كبيرة & 0,97 & 3,86 & يشرف مص على تفعيل المعلمين للإمكانات المتوفرة في & 32 \\
\hline كبيرة & 0,98 & 3,71 & يعمل على توظيف أساليب إنشر افية متتو عة. & 36 \\
\hline كبيرة & 1,30 & 3,40 & يشارك في بر امج تبادل الزيار ات مع مدارس أخرى. & 29 \\
\hline كبيرة & $\mathbf{0 , 6 4}$ & 4,03 & معدل مجال المتابعة الميدانية & \\
\hline
\end{tabular}

يلاحظ من الجدول أعلاه أن معدل ممارسـة معلمي التربيـة الإسـامية الأوائل لمهامهم الإشر افية

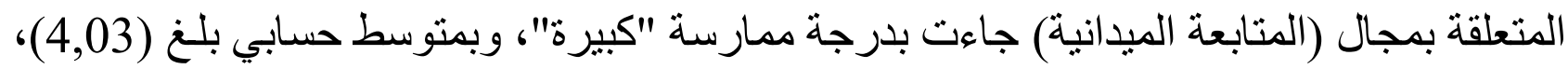

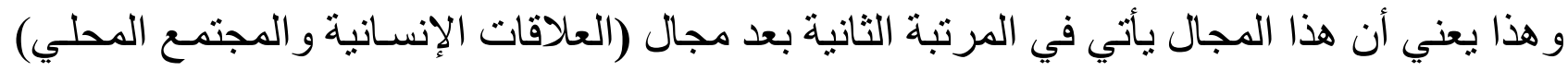

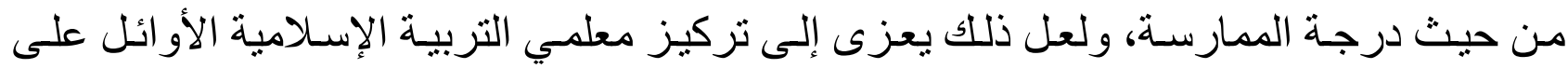

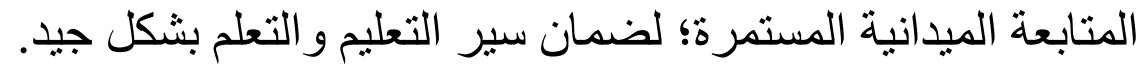

تتفق هذه النتيجة مع نتائج دراسة كل من (القطبطي،2007؛ المحروقية،2007؛ العامري، 2008/أ؛ العامري، 2008/ب) التي حصل فيها مجال المتابعة الميدانية على درجة ممارسة كبيرة.

ويتضح من الجدول أن المتوسطات الحسـابية لمهام مجال المتابعة الميدانية تر اوحت بين (30)

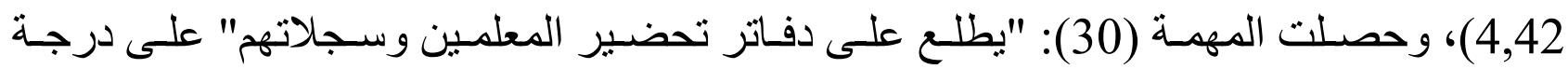

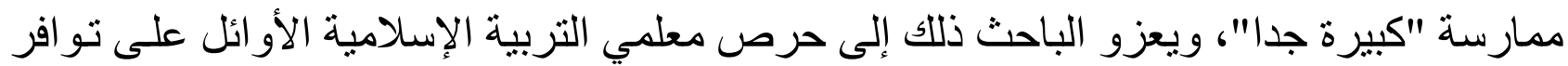

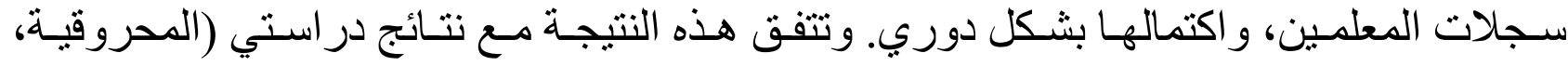

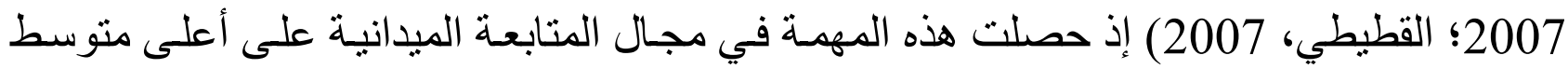




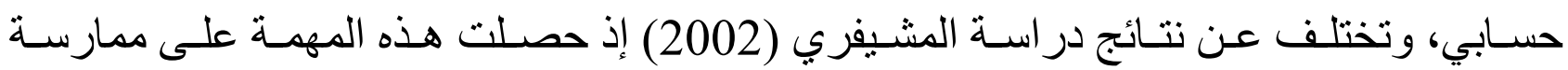
منوسطة في مجال تطوير خبر ونغ نقات المعلمين.

وحصلت المهــة (29): "يشـارك في بـرامج تبـادل الزيـارات مـع مدارس أخرى" على التسلسل

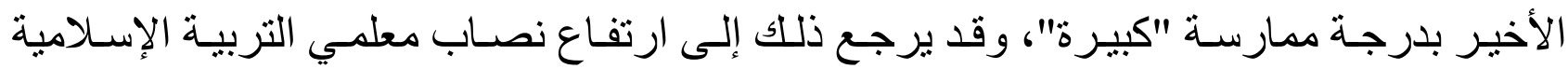

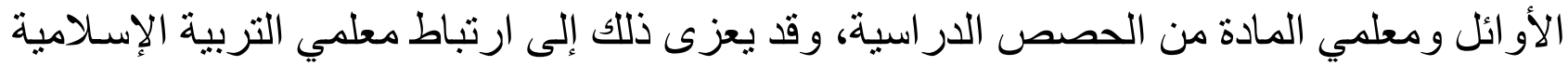

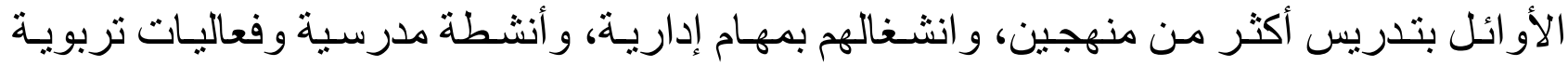

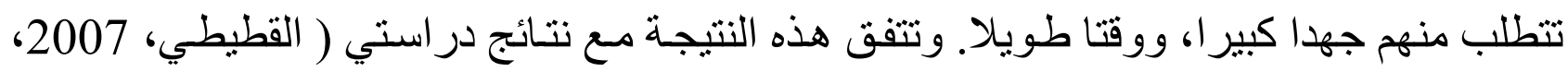
المحروقية، 2007) إذ حصلت هذه المهمة في مجال المتابعة الميدانية على أدنى منوسط هذئ حسابي.

\section{المجال الخامس: مجال التدريب والإنماء المهني:}

يبين الجدول الآتي نتائج استجابة العينة للمهام الإشر افية المتعلقة بمجال التدريب والإنماء المهني

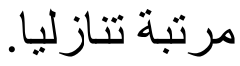

الجدول (6) المهام الإثر افية المتعلقة بمجال التدريب و الإنماء المهني ترنيبا تتازليا

\begin{tabular}{|c|c|c|c|c|}
\hline المدارجة & الانمراف & المتوسط المسابي & 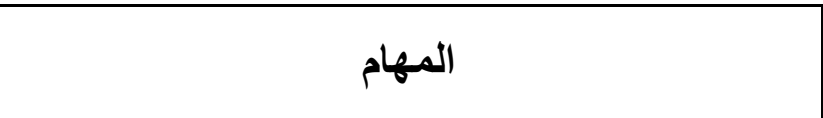 & المهمة \\
\hline كبيرة & 0,96 & 3,82 & يحدد الحاجات التدريبية للمعلمين. & 37 \\
\hline كبيرة & 1,00 & 3,82 & بنفذ بر امج تدريبية لتطوير مستوى أداء المعلمين. & 39 \\
\hline 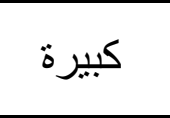 & 1,04 & 3,75 & والبر امج المعلمين على الإلتحاق بالدورات التدريبية & 41 \\
\hline كبيرة & 1,02 & 3,72 & يشارك في إعداد البر امج التدريبية. & 38 \\
\hline 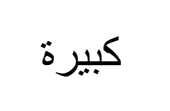 & 1,13 & 3,67 & المدرسة. عحرص تنفيذ دروس مشاهدة أنموذجية في & 40 \\
\hline 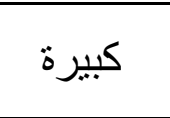 & 1,08 & 3,63 & المعلمين انتقال أثر التّريب لتحسين مستوى أداء & 45 \\
\hline متوسطة & 1,14 & 3,32 & وخبرد اتهم. المعلمين بمقالات ونشرات تثري معلوماتهم & 42 \\
\hline متوسطة & 1,13 & 3,22 & يحفز المعلمين للقيام ببحوث ونتائج در اسات تربوية. & 43 \\
\hline متوسطة & 1,14 & 2,97 & يقو م بإعداد بحوث ونتائج در اسات تربوية. & 44 \\
\hline كبيزة & 0,81 & 3,55 & معدل مجال التدريب والإنماء المهني & \\
\hline
\end{tabular}

يلاحظ من الجدول أعلاه أن درجـة ممارسـة معلمي التربيـة الإسـامية الأوائل لمهامهم الإشـر افية

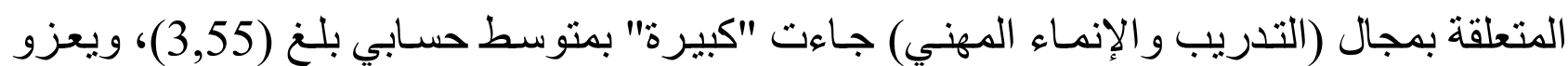

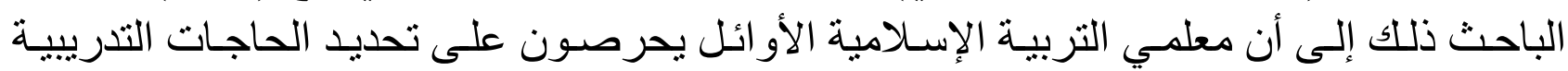
للمعلمين، وتتفيذ البرامج التدريبية لتطوير مستوى أداء المعلمين. 
تتفق هذه النتيجـة مـع نتـائج الدر اسـات الآتيـة: در اسـة العريمي (2004) التـي احتـل فيهـا مجـال التدريب المرتبة قبل الأخيرة، ودر اسة كل من (القطيطي، 2007؛ المحروقية، 2007؛ العـامري،

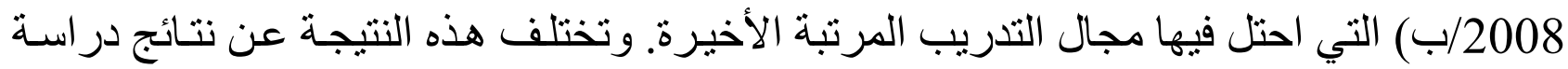

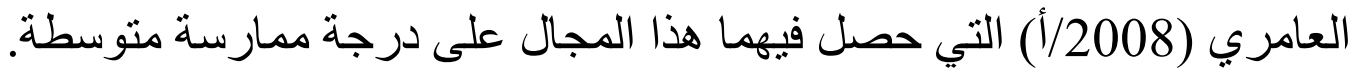

ويتضح من الجدول أعلاه أن المتوسطات الحسابية لمهام مجال التدريب و الإنمـاء المهني تر اوحت

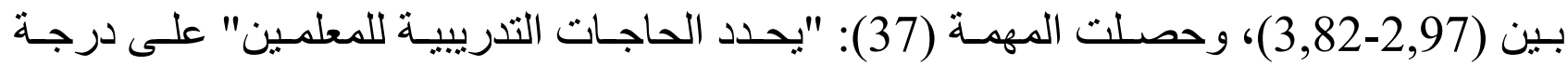

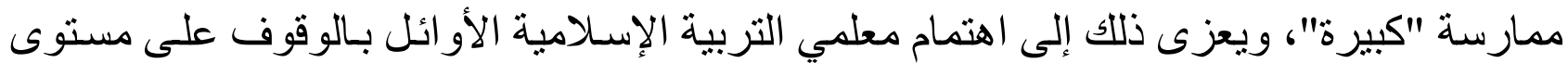
أداء معلمي المادة، والوقوف على وبعى درجة كفايتهم للمهار ات التدريسية.

وحصلت المهام: (44، 43، 42) على درجـة ممارسـة متوسطة، ونلاحظ أن هذه المهام مرتبطة

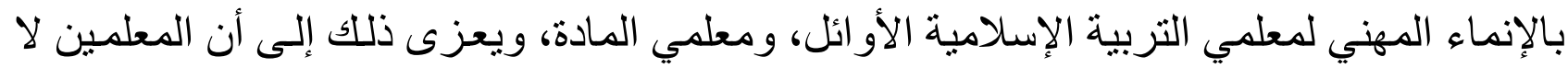

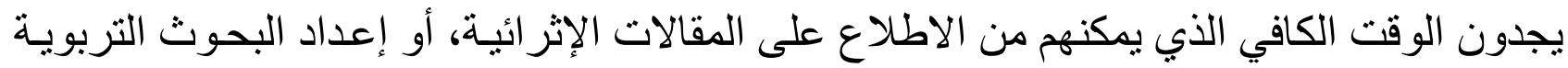

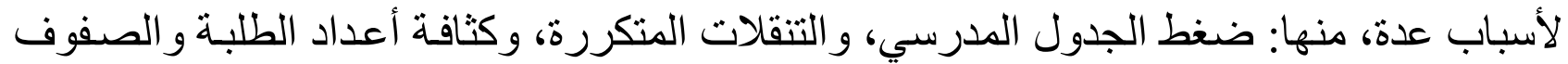

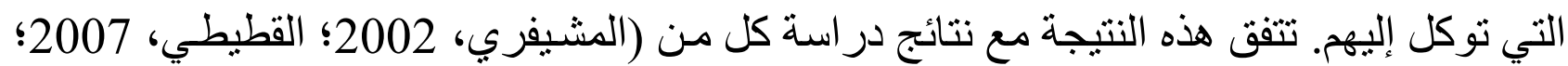

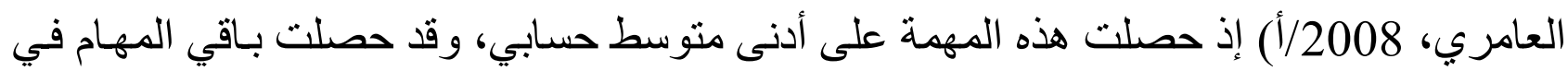
هذا المجال على درجة ممارسة كبيرة.

\section{المجال الخامس: مجال العلاقات الإنسانية والمجتمع المحلي:}

يبين الجدول الآتـي نتـائج اسـتجابة العينـة للمهـام الإشـر افية المتعلقـة بمجـال العلاقـات الإنسـانية

و المجتمع المحلي مرتبة تنازليا. الجدول (7) المهام الإشر افية المتعلقة بمجال العلاقات الإنسانية و المجتمع المحلي مرتبة تنازليا

\begin{tabular}{|c|c|c|c|c|}
\hline الممارسة & المعياري & المتوسط & 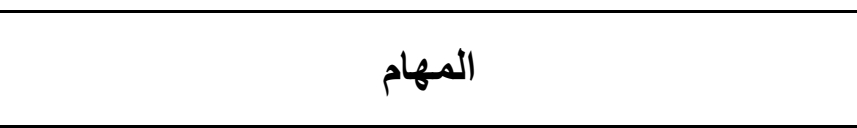 & 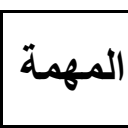 \\
\hline كبيرة & 0,63 & 4,73 & يتجنب إحر اج المعلمين في الموقف الصفي. & 46 \\
\hline كبيرة & 0,59 & 4,63 & ويني علاقات إيجابية مع إدارة المدرسة و المعلمين & 52 \\
\hline كبيرة & 0,62 & 4,59 & يتقبل وجهات نظر المعلمين. & 47 \\
\hline كبيرة & 0,67 & 4,52 & يتعامل مع المعلمين بموضو عية. & 48 \\
\hline كبيرة & 0,72 & 4,49 & يعزز الدافعية والحماس لدى المعلمين. & 49 \\
\hline كبيرة & 0,86 & 4,33 & يشارك بفاعلية في الأنشطة المدرسية و المجتمعية. & 50 \\
\hline كبيرة & 0,78 & 4,18 & يوجه المعلمين لتوظيف إمكانات البيئة المحلية. & 51 \\
\hline
\end{tabular}


IJASOS- International E-Journal of Advances in Social Sciences, Vol. VI, Issue 16, April 2020

\begin{tabular}{|c|c|c|c|c|}
\hline كبيرة & 0.90 & 4,06 & يعزز دور أولياء الأمور في العملية التربوية. & 53 \\
\hline كبيرة & 1,07 & 3,76 & 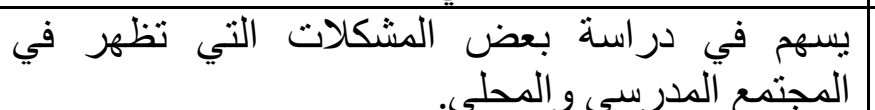 & 54 \\
\hline جبيرة & $\mathbf{0 , 5 1}$ & 4,36 & معدل مجال العلاقات الإنسانية والمجتمع المحلي & \\
\hline
\end{tabular}

يلاحظ من الجدول أعلاه أن معدل ممارسـة معلمي التربيـة الإسـلامية الأوائل لمهامهم الإشـر افية

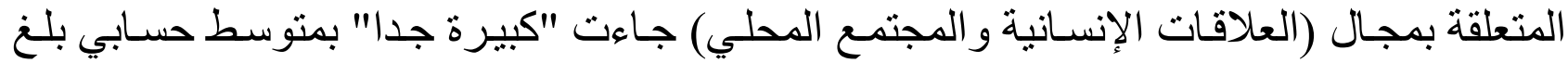

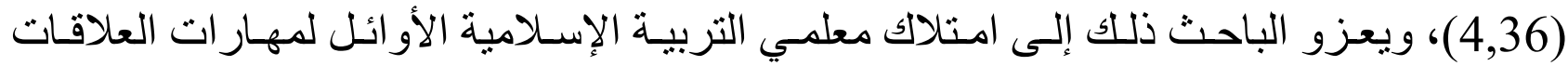

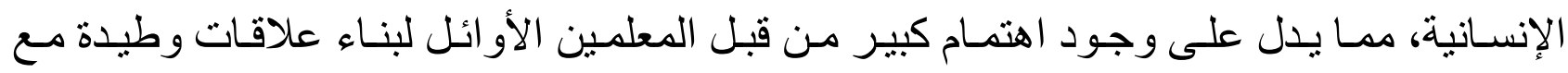

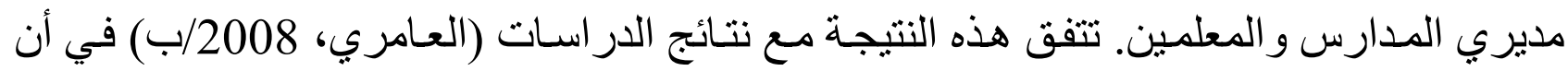

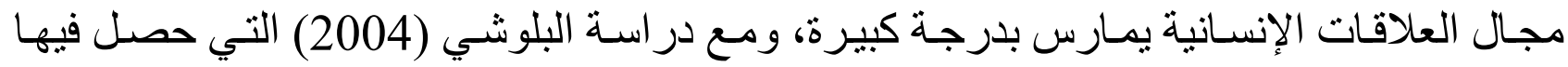

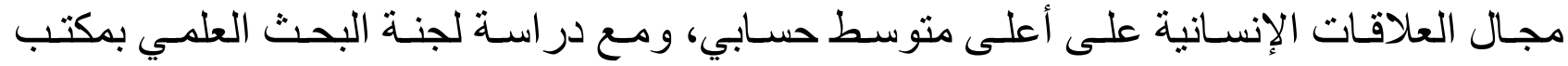
الإشر اف التربوي بسمائل (2006).

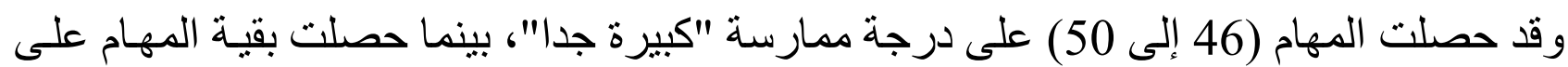

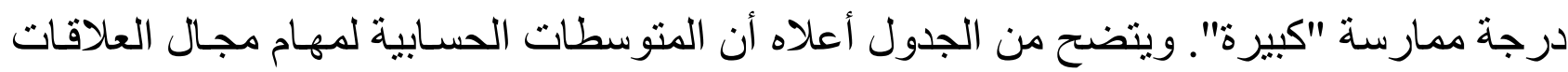

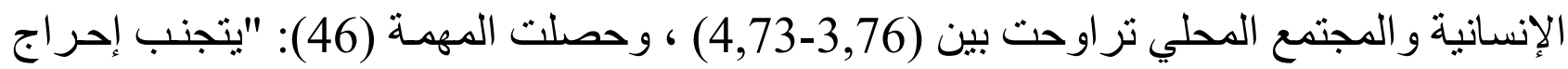

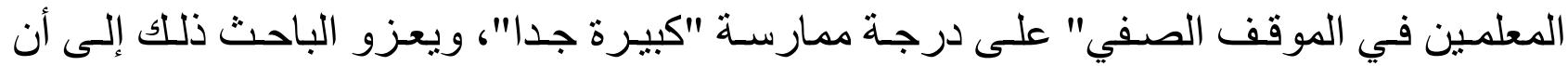

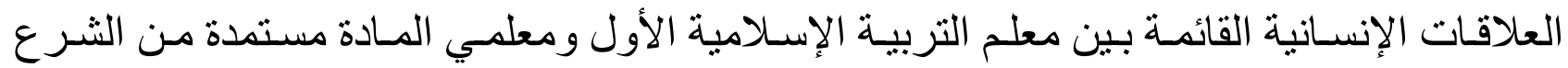

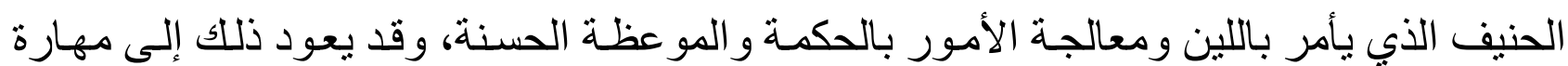
المعلم الأول في التصرف في المو اقف ومعالئ المختلفة.

وحصـلت المهــة (54) على أقل المتوسطات الحسـابية، وربمـا يعود ذللك إلى تصـور المعلمين

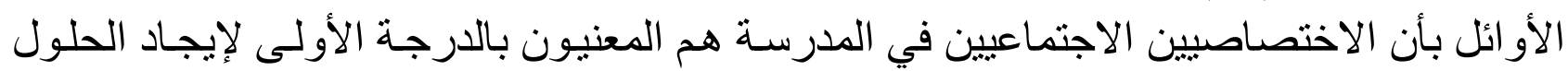
المناسبة للمشكلات التي تظهر في المجتمع المدرسي.

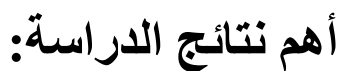

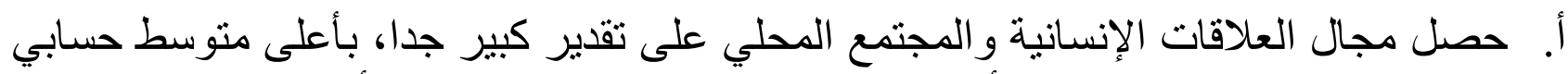

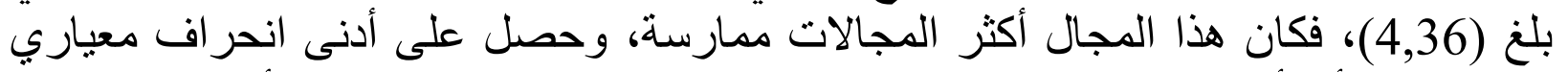

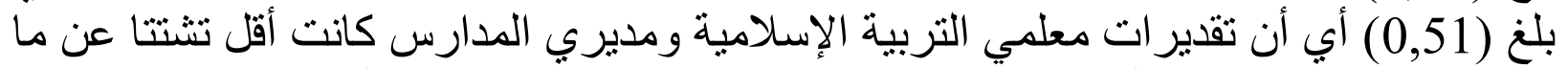

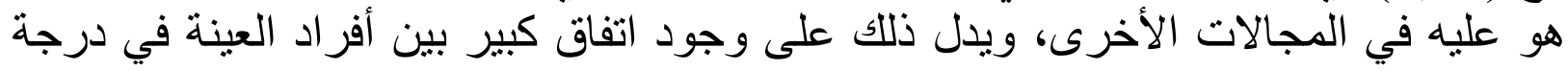
الممارسة للمهام الإشر افية المتعلقة بهذا المجال المال.

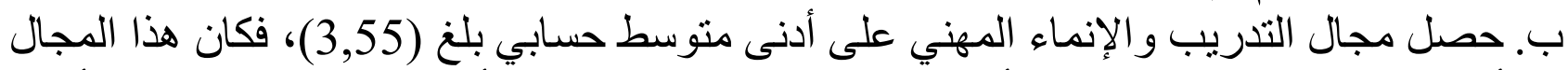

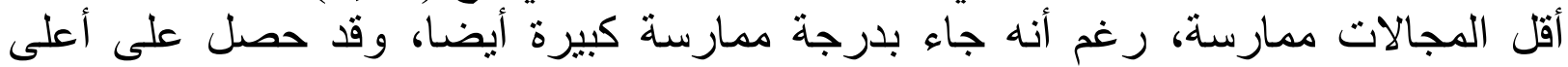
انحراف معياري بلغ (0,81)، أي أن تقديرات معلمي التربية الإسلامية ومديري النية المدارس النس 


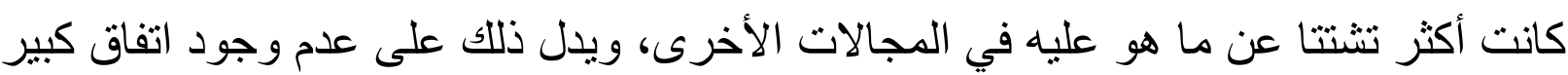
بين أفر اد العينة في درجة الممارسة للمهام الإشر افية المتعلقة بهذا المجال المال.

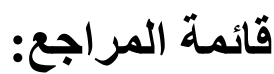
الثمالي، عبد الرزاق عبد الرحيم عوض الله. (1997). وظائف الإثر اف التربوي، ومدى تنفيذ المشرف التربن التربوي

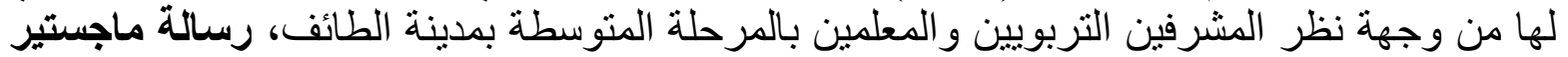
غير منشورة، كلية التربية، جامعة أم القرى.

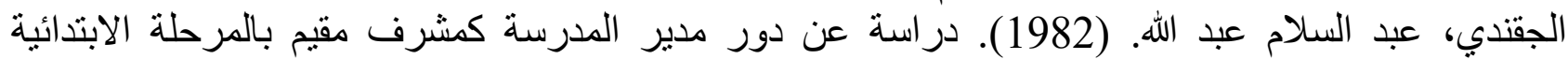

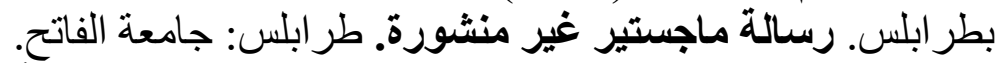

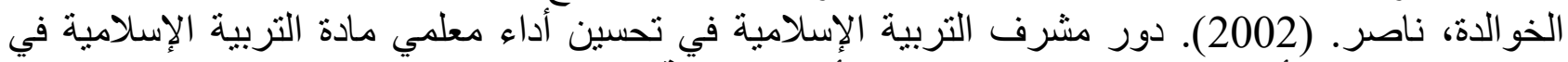

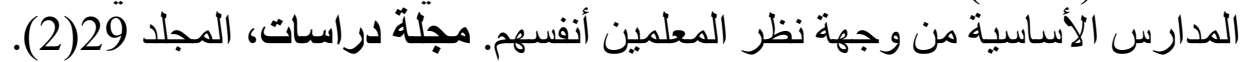

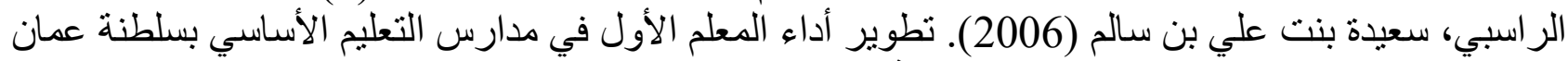

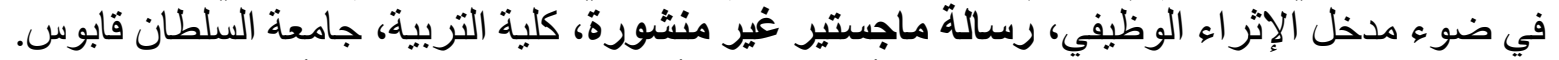

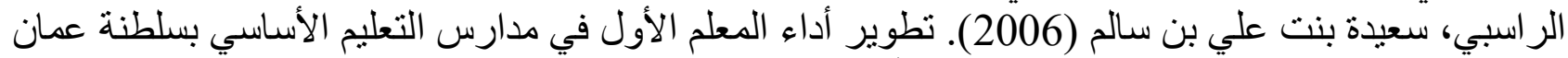

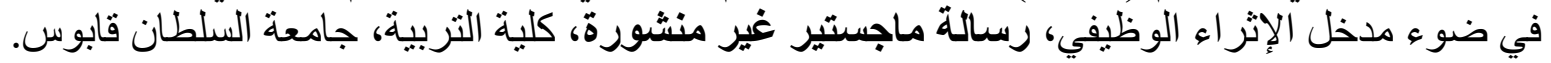

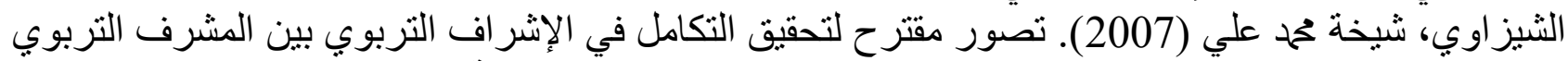

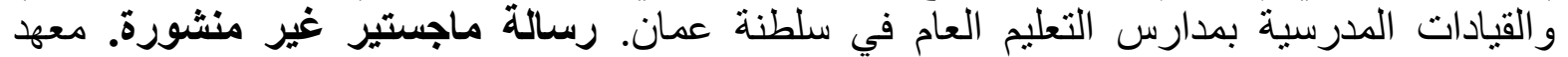
البحوث و الدراسات العربية جامعة الدول العربية العربية القاهرة.

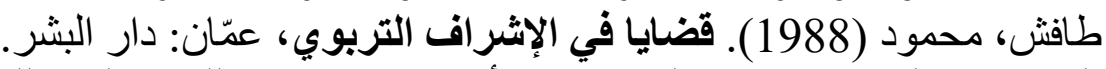

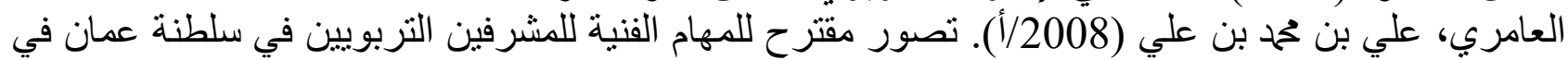

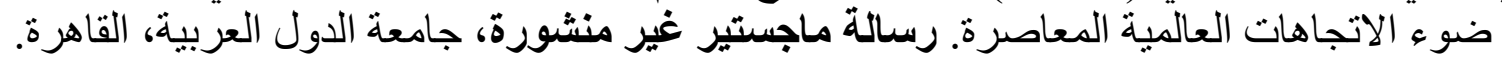

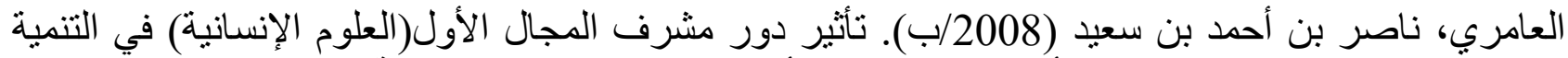

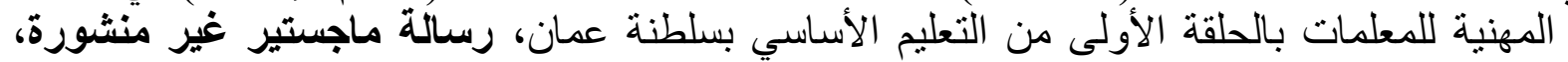

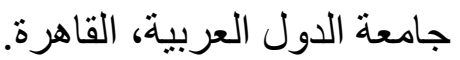

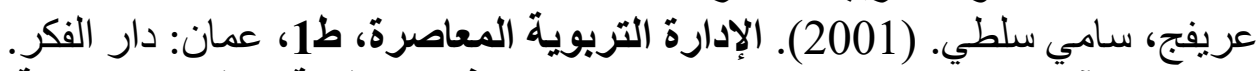

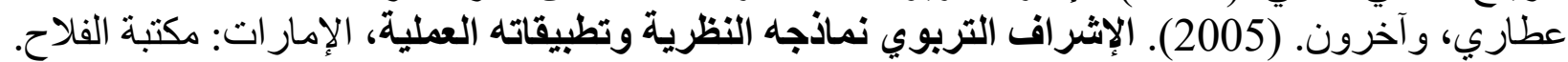

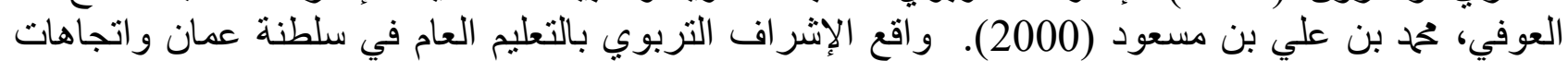

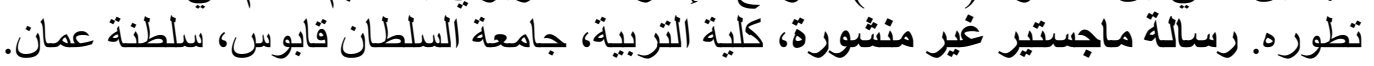

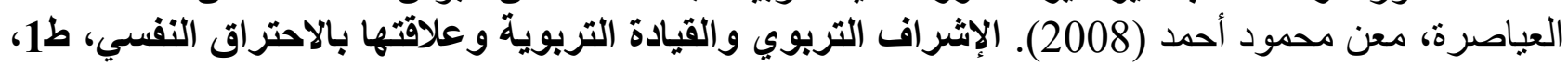
عمان: دار الحامد للنشر و التوزيع. (2008) الإثران الفهدي، عبد الله بن سيف (2008). المعلم الأول. التطوير التربوي. العدد 44 مطابع مؤسسة عُمان للصحافة

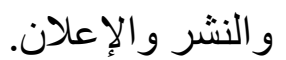
القطيطي، حمح بن علي (2007). مدى ممارسة معلمي العلوم الأو ائل لمهامهم الإثر افية من وجهة نظر هم ونظر

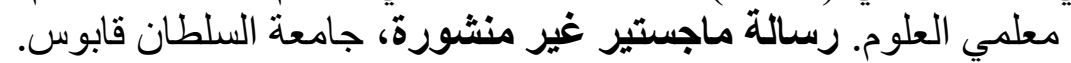
اللواتية، طاهرة بنت عبدالخالق (2006). المعلم والششرف. التطوير التربوي، العدد323، المطابع العالمية، سلطنة عمان

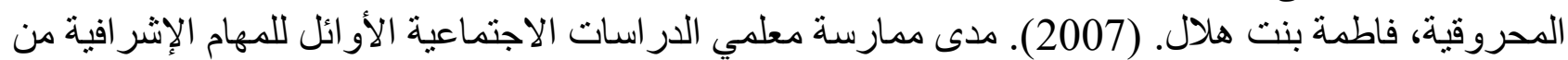
وجهة نظر مشرفي المادة ومعلميها. رسالة ماجستير غير منشير منشورة، كلية التربية، جامعة الإنية السلطان قابوس. المشيفري، سالم بن علي. (2003). الدور المنوقع و الفعلي للمشرف التربوي في التنمية المهنية للمعلمين في

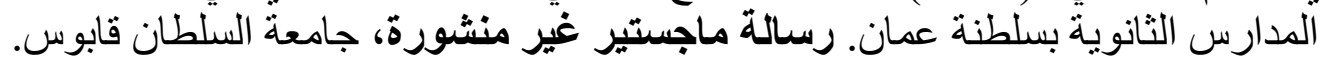

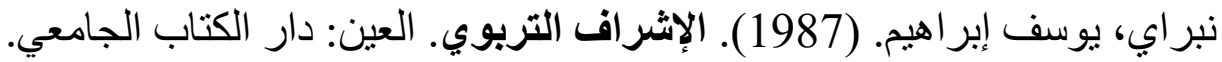




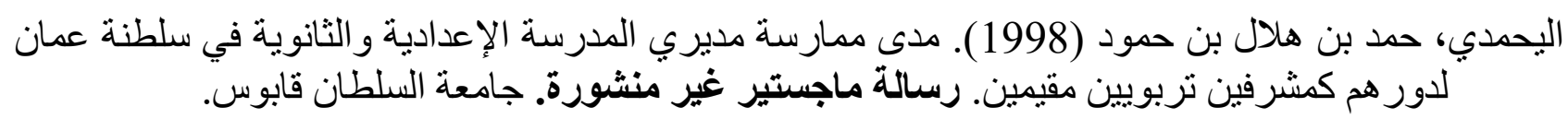

\section{ARABIC REFERENCES IN ROMAN ALPHABET}

Althamali, Eabd Alrazzaq Eabd Alrahim Eiwad Allh. (1997). Wazayif Al'iishraf Altarbwii, Wamadaa Tanfidh Almushrif Altarbuii Laha Min Wijhat Nazar Almushrifin Altarbuiiyn Walmuealamin Bialmarhalat Almutawasitat Bimadinat Altayif, Risalat Majstayr Ghyr Manshuratin, Kuliyat Altarbiati, Jamieatan 'Am Alquraa.

Aljaqnadiu, Eabd Alsalam Eabd Allh. (1982). Dirasatan Ean Dawr Mudir Almadrasat Kimasharif Muqim Bialmarhalat Alaibtidayiyat Bitarabilis. Risalat Majstayr Ghyr Manshurati. Tarabulsa: Jamieat Alfatih.

Alkhawalidat, Nasir. (2002). Dawr Musharaf Altarbiat Al'iislamiat Fi Tahsin 'Ada' Muelimii Madat Altarbiat Al'iislamiat Fi Almadaris Al'asasiat Min Wijhat Nazar Almuealimin 'Anfusahim. Majalat Darasatin, Almajlid 29(2).

Alraasibi, Saeidat Bnt Eali Bin Salim (2006). Tatwir 'Ada' Almuelim Al'awal Fi Madaris Altaelim Al'asasii Bisiltanat Eamman Fi Daw' Madkhal Al'iithra' Alwazifii, Risalat Majstayr Ghyr Manshurati, Kuliyat Altarbiati, Jamieat Alsultan Qabws.

Alraasibi, Saeidat Bnt Eali Bin Salim (2006). Tatwir 'Ada' Almuelim Al'awal Fi Madaris Altaelim Al'asasii Bisiltanat Eamman Fi Daw' Madkhal Al'iithra' Alwazifii, Risalat Majstayr Ghyr Manshurati, Kuliyat Altarbiati, Jamieat Alsultan Qabws.

Alshayzawiu, Shaykhat Muhamad Eali (2007). Tasawur Muqtarah Litahqiq Altakamul Fi Al'iishraf Altarbwii Bayn Almushrif Altarbawii Walqiadat Almadrasiat Bimadaris Altaelim Aleami Fi Saltanat Euman. Risalat Majsatayr Ghyr Manshurat. Maehad Albihawth Waldirasat Alearabiat Jamieat Alduwal Alearabiat Alqahirat.

Tafash, Mahmud (1988). Qadayaan Fi Al'iishraf Altarbwi, Emman: Dar Albashr.

Aleamiriu, Eali Bin Muhamad Bin Eali (2008/A). Tasawur Muqtarah Lilmiham Alfaniyat Lilmushrifin Altarbuiiyn Fi Saltanat Eamman Fi Daw' Alaitijahat Alealamiat Almueasirati. Risalat Majsatayr Ghyr Manshurati, Jamieat Alduwal Alearabiati, Alqahirat.

Aleamiriu, Nasir Bin 'Ahmad Bin Saeid (2008/Ba). Tathir Dawr Musharaf Almajal Al'uwala(Alieilum Al'iinsaniata) Fi Altanmiat Almihniat Lilmuealamat Bialhulqat Al'uwlaa Min Altaelim Al'asasii Bisiltanat Eumaan, Risalat Majsatayr Ghyr Manshurati, Jamieat Alduwal Alearabiati, Alqahirat.

Earifij, Sami Sultuy. (2001). Al'iidarat Altarbawiat Almueasiratu, Ta1, Eamana: Dar Alfikr. Eitari, Wakharuna. (2005). Al'iishraf Altarubuwiu Namadhijuh Alnazariat Watatbiqatih Aleamaliat, Al'imarat: Maktabat Alfalahi.

Aleufi, Muhamad Bin Eali Bin Maseud (2000). Waqie Al'iishraf Altarbuii Bialtaelim Aleami Fi Saltanat Eamman Waitijahat Tatawurihi. Risalat Majstayr Ghyr Manshurati, Kuliyat Altarbiati, Jamieat Alsultan Qabus, Saltanat Eaman.

Aleayasirat, Maen Mahmud 'Ahmad (2008). Al'iishraf Altarbawiu Walqiadat Altarbawiat Waealaqatuha Bialaihtiraq Alnafsii, Ta1, Eamana: Dar Alhamid Lilnashr Waltawzie.

Alfahdiu, Eabd Allah Bin Sayf (2008). Almuelim Al'awla. Altatwir Altarbui. Aleadad 44 Matabie Muasasat Euman Lilsahafat Walnashr Wal'iielan.

Alqatiti, Muhamad Bin Eali (2007). Madaa Mumarasat Muelimii Aleulum Al'awayil Limahamihim Al'iishrafiat Min Wijhat Nazarihim Wanazar Muelimii Aleulumi. Risalat Majstayr Ghyr Manshurat, Jamieat Alsultan Qabws.

Allawatiatu, Tahirat Bnt Eabdalkhaliq (2006). Almuelam Walmusharif. Altatwir Altrbwi, Aledd32, Almatabie Alealamiatu, Saltanat Eamman.

Almahruqiat, Fatimat Bnt Hulal. (2007). Madaa Mumarasat Muelimii Aldirasat Alaijtimaeiat Al'awayil Lilmahami Al'iishrafiat Min Wijhat Nazar Musharifi Almadat Wamuelimiha. Risalat Majstayr Ghyr Manshuratin, Kuliyat Altarbiati, Jamieat Alsultan Qabus. 
Almushifriu, Salim Bin Eali. (2003). Aldawr Almutawaqae Walfieliu Lilmushrif Altarbawii Fi Altanmiat Almihniat Lilmuelimin Fi Almadaris Alththanawiat Bisiltanat Euman. Risalat Majstayr Ghyr Manshurat, Jamieat Alsultan Qabws.

Nabray, Yusif 'librahim. (1987). Al'iishraf Altrbwy. Aleayn: Dar Alkitab Aljamiei.

Alyahmadi, Hamd Bin Hilal Bin Hamuwd (1998). Madaa Mumarasat Mudiri Almadrasat Al'iiedadiat Walthaanawiat Fi Saltanat Eamman Lidawrihim Kimushrifin Turbuiiyn Muqimina. Risalat Majstayr Ghyr Manshuratin. Jamieat Alsultan Qabws.

\section{REFERENCE LIST}

Ali, Mehrunnisa, Ahmad (2000). Supervision for teacher development: an alternative model for Pakistan. International Journal Educational Developmental, Int. J. of Educational Developmental 20, P. 177-188 (Canada).

Click, Phyllis(1975). Administrion of Schools for Young Children (United Sates. Of America: Litton: Educational Publishing, Inc).

Duquette, Cheryll. (1994). The Role of the Cooperating Teacher in a School-Based Teacher Education Program: Benefits and Concerns, Teaching \& Teacher Education, 10(3), 345-353.

Male, Trevor; Daresh, John (1997). Crossing the Border into School Leadership: Experiences Newly Appointed Headteachers in England. ED 412643 